\title{
Coordination of signalling networks and tumorigenic properties by $A B L$ in glioblastoma cells
}

\author{
Fabienne Lamballe ${ }^{1, *}$, Sara Toscano ${ }^{1, *}$, Filippo Conti ${ }^{1, *}$, Maria Arechederra ${ }^{1}$, Nathalie \\ Baeza $^{2}$, Dominique Figarella-Branger ${ }^{2}$, Françoise Helmbacher ${ }^{1}$ and Flavio Maina ${ }^{1}$ \\ ${ }^{1}$ Aix-Marseille Université, CNRS, Developmental Biology Institute of Marseille (IBDM), Parc Scientifique de Luminy, Marseille, \\ France \\ ${ }^{2}$ Aix-Marseille Université, Inserm, CRO2 UMR S911, Marseille, France \\ * These authors have contributed equally to the work \\ Correspondence to: Flavio Maina, email: flavio.maina@univ-amu.fr \\ Keywords: ABL, migration and invasion, tumorigenicity and self-renewal, RTK signalling, glioblastomas \\ Received: August 02, $2016 \quad$ Accepted: September 29, $2016 \quad$ Published: October 09, 2016
}

\section{ABSTRACT}

The cytoplasmic tyrosine kinase ABL exerts positive or negative effects in solid tumours according to the cellular context, thus functioning as a "switch modulator". The therapeutic effects of drugs targeting a set of signals encompassing $A B L$ have been explored in several solid tumours. However, the net contribution of ABL inhibition by these agents remains elusive as these drugs also act on other signalling components. Here, using glioblastoma (GBM) as a cellular paradigm, we report that ABL inhibition exacerbates mesenchymal features as highlighted by down-regulation of epithelial markers and up-regulation of mesenchymal markers. Cells with permanent ABL inhibition exhibit enhanced motility and invasive capabilities, while proliferation and tumorigenic properties are reduced. Intriguingly, permanent ABL inhibition also interferes with GBM neurosphere formation and with expression of stemness markers in sphere-cultured GBM cells. Furthermore, we show that the molecular and biological characteristics of GBM cells with impaired ABL are reversible by restoring ABL levels, thus uncovering a remarkable plasticity of GBM cells to ABL threshold. A phosphosignalling screen revealed that loss of tumorigenic and self-renewal properties in GBM cells under permanent $A B L$ inhibition coincide with drastic changes in the expression and/or phosphorylation levels of multiple signalling components. Our findings identify $A B L$ as a crucial player for migration, invasion, proliferation, tumorigenic, and stemcell like properties of GBM cells. Taken together, this work supports the notion that the oncogenic role of ABL in GBM cells is associated with its capability to coordinate a signalling setting that determines tumorigenic and stem-cell like properties.

\section{INTRODUCTION}

The non-receptor tyrosine kinase (RTK) ABL influences behaviour of cells by regulating migration, invasion, survival, and proliferation, according to the cellular context [1-3]. ABL was shown to regulate cell membrane protrusions by modulating actin polymerization [4] and to control cell polarity by acting on polarized junctional dynamics in drosophila embryos $[5,6]$. Through these mechanisms, ABL influences cell motility and directional collective cell migration, processes occurring during embryogenesis and cancer. ABL also participates in molecular events regulating the epithelialmesenchymal transition [7]. Genetic studies using knock- out mice have highlighted the developmental requirement of Abl in cardiac growth [8], hepatocyte survival [9], neurulation $[10,11]$, and together with its homologue Arg in basement membrane integrity and cortical lamination in the cerebellum [12]. Furthermore, Abl influences mouse female fertility during chemotherapy [13] and its alteration may impact neurodegenerative diseases and therapies [14].

The BCR-ABL fusion protein, generated following translocation of $A B L$ to the $B C R$ gene, leads to constitutive activation of the ABL tyrosine kinase in $95 \%$ of chronic myeloid leukemia and cells depend on BCR-ABL activity for the execution of the oncogenic program [15]. In solid tumours, ABL is constitutively activated in breast carcinomas [16], non-small cell lung carcinomas 
[17], melanoma [18], anaplastic thyroid cancers [19], hepatocellular [20], ovarian [21], and gastric carcinomas [20]. In these tumours, ABL alterations occur through mechanisms distinct from gene mutation/translocation $[1,3,22,23]$. For example, deregulated ABL is found in cancer cells with aberrant activation of RTKs, such as PDFGR, FGFR, EGFR, MET, KIT, and IGF1R [1, 3, 22]. In this context, a number of apparently contradicting results have shown that $\mathrm{ABL}$ acts as a signalling promoter $[16,18,20,24-27]$ or as a signalling inhibitor [28-31] of a given biological response, thus functioning as a "switch modulator". These opposing effects are most likely related to how $\mathrm{ABL}$ is integrated into the oncogenic signalling machinery operating in cells. We have previously demonstrated that $\mathrm{ABL}$ acts as a signalling node interconnecting RTK and p53 "core pathways" during embryogenesis [9] and in cancer [20]. The implication of ABL in regulating the biology of cancer cells and the availability of clinically-relevant $\mathrm{ABL}$ antagonists has fostered exploration of their use in preclinical models and in clinics $[1,3,22]$. Most promising agents include Imatinib (Gleevec, STI571), Nilotinib, and Dasatinib. However, action of these antagonists is not restricted to ABL inhibition: Imatinib blocks PDGFR, KIT, ABL and its homologue ARG at comparable concentration levels [32]. Nilotinib is a second generation inhibitor that blocks preferentially ABL/ARG than PDGFR and KIT [32]. Dasatinib, a dual SRC/ABL inhibitor that also targets EGFR and KIT, elicits anti-tumorigenic effects in preclinical studies [33, 34]. While ABL antagonists are effective in clinics for CML treatment [35], their failure or limited success on solid tumours left open the debate as to whether they are ineffective or whether they must be used on patient subgroups characterised by a specific molecular signature. Furthermore, the use of ABL antagonists in combination with other agents for synergistic treatments remains an attractive possibility, although challenged by the limitless possibilities of drug combinations [3].

Glioblastoma multiforme (GBM), the most common and aggressive primary brain tumour in adults, can develop de novo (primary GBM) or through malignant progression of a low grade astrocytoma (secondary GBM) [36]. Patients suffering of GBM have a poor prognosis with a median survival rate of 12-15 months despite heavy clinical management including surgical ablation combined with Temozolomide chemotherapy and radiotherapy [37, 38]. Limited response to current GBM therapies is attributed to the presence of cells with stem-cell like properties, the so-called cancer stem cells [39-41]. These cells display the characteristic features of unlimited growth, self-renewal, differentiation, and are thought to be responsible for initiation, maintenance, and recurrence of tumours $[42,43]$. A systematic analysis of (epi)genetic alterations in GBM led to the discovery of three main "core pathways" that are concomitantly altered: RTK signalling, p53, and RB "core pathways" [44]. The identification of altered molecular components through this and other GBM genome studies has boosted cellular and preclinical exploration of targeted molecular therapies to treat GBM. Relevance of RTKs in GBM is further supported by the constitutive expression of distinct RTKs that renders cells resistant to treatment with a single RTK blocking agent, a mechanism known as "RTK swapping" $[45,46]$. For example, in a subgroup of GBM cells with constitutive activation of PDGFR, EGFR, and MET, the combination of Imatinib, SU11274, and Gefitinib elicits maximal response of GBM cells to treatment [45]. In GBMs with aberrant RTKs, ABL has been reported to be activated by and required for PDGFR function [47]. Reverse phase protein lysate arrays on high-grade versus lower-grade gliomas have identified ABL among the 12 most powerful discriminators [48]. Focal accumulation of ABL protein was also detected by immunolabelling in a proportion of GBM patients [49]. However, the extent to which ABL signalling influences GBM cell biology still remains elusive as: a) ABL and PDGFR reciprocally regulate their phosphorylation levels in GBM cells [47]; b) the beneficial effects of Imatinib cannot be attributed to one single target, since it simultaneously inhibits PDGFR and ABL (in addition to KIT) $[45,50]$. In the present study, we used GBM as a cellular paradigm to explore whether and how permanent impairment of ABL function impacts biological and tumorigenic properties.

\section{RESULTS}

\section{ABL inhibition leads to morphological and molecular changes in GBM cells}

The U87 GBM cell line has been extensively used to assess the effectiveness of several drugs targeting signalling components such as RTK inhibitors $[45,51$ 54]. We therefore used U87 as a GBM cell paradigm to assess the molecular and cellular consequences of $\mathrm{ABL}$ inhibition. We interfered ABL functions by two complementary approaches, involving either short hairpin RNA (shRNA) interference or pharmaceutical inhibitors. To achieve successful ABL targeting with the shRNA strategy, the efficiency of 3 different shRNA sequences to down-regulate $\mathrm{ABL}$ was tested in transfected cells after selection (Supplementary Table 1). Efficient downregulation of $\mathrm{ABL}$, but not $\mathrm{ARG}$, mRNA and protein levels was obtained by shAbl-1 $[20,55]$, shAbl-2, and to a lesser extent by shAbl-3 compared to either parental cells or cells transfected with a scrambled shRNA (both conditions further designed as control U87 cells; Figure 1A, 1B, and Supplementary Figure 1A). To reinforce specificity of the shRNA sequences used for targeting ABL, U87 cells carrying the shABL-1 plasmid were transfected with a vector expressing wild-type ABL. 
A

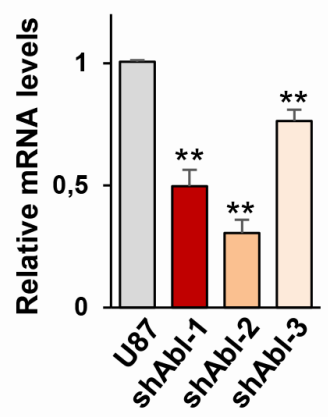

C

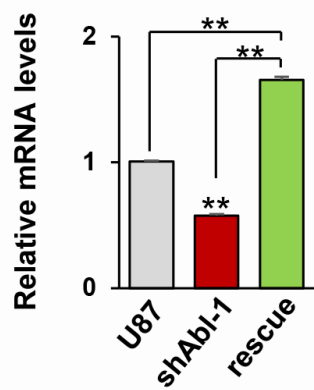

B

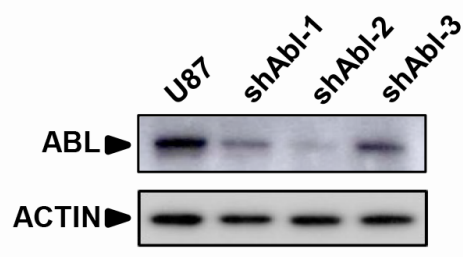

D

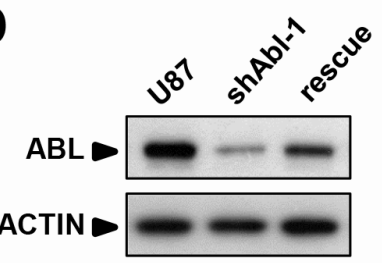

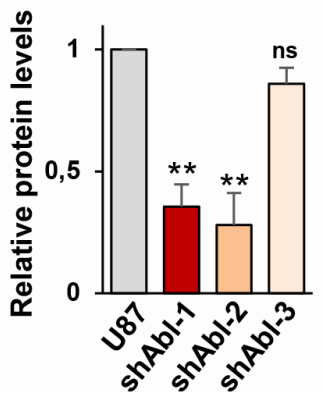

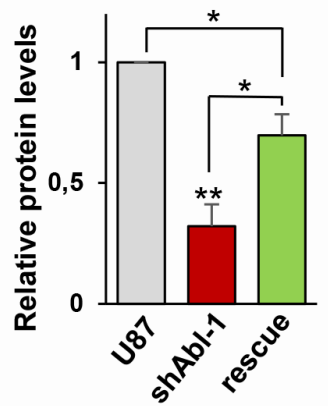

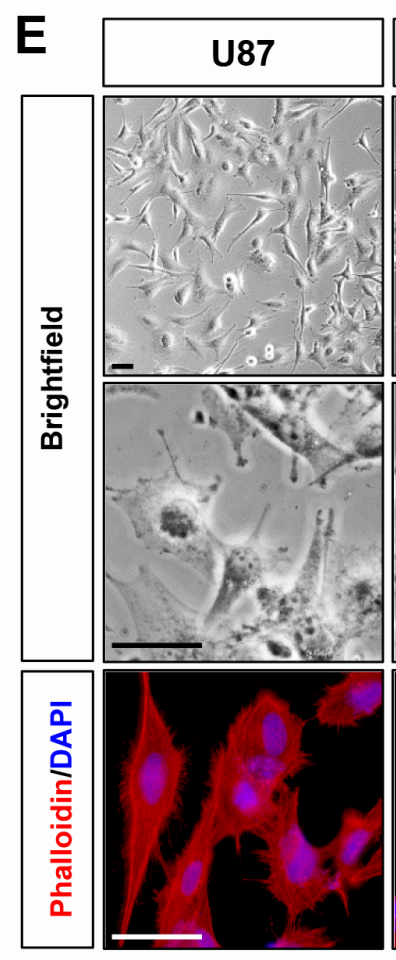
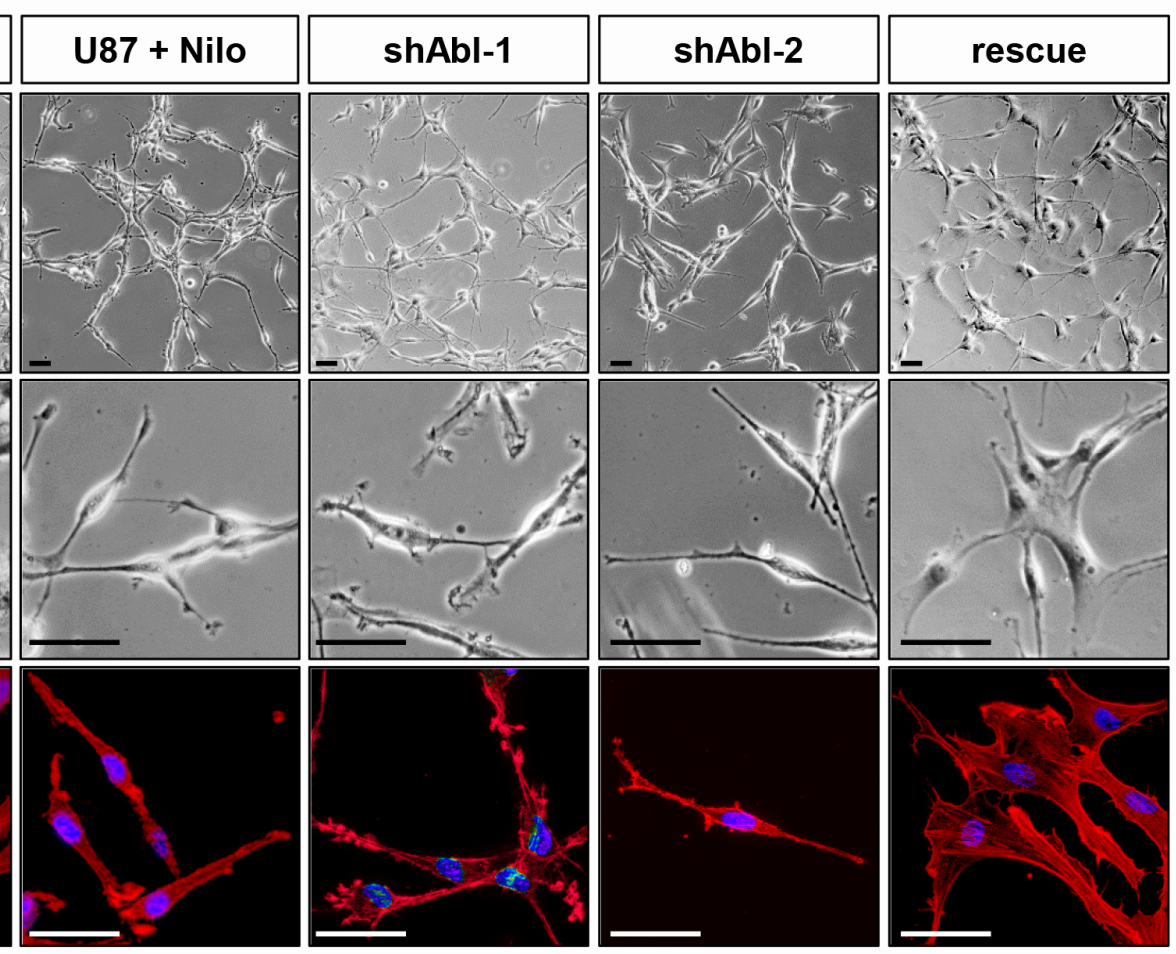

Figure 1: ABL impairment confers mesenchymal morphology of U87 cells. A, B. RT-qPCR (A) and western blot (B) analyses of ABL expression levels in U87 ${ }^{\text {shABL }}$ cells (U87 transfected with shABL-1, shABL-2, and shABL-3) compared to controls. Note ABL downregulation in $\mathrm{U}^{\mathrm{shABL}}$ cells versus controls (for shABL-1: mRNA 0.5 \pm 0.06 fold change; protein: $0.35 \pm 0.09$ fold change; for shABL-2: mRNA $0.3 \pm 0.05$ fold change; protein: $0.28 \pm 0.13$ fold change; for shABL-3: mRNA $0.76 \pm 0.04$ fold change; protein: $0.86 \pm 0.06$ fold change). C., D. RT-qPCR (C) and western blot (D) analyses of ABL expression levels in U87 $7^{\text {rescue }}$ compared to U87 $7^{\text {shABL }}$ (U87 transfected with shABL-1) cells and controls. Note increased ABL levels in U87 $7^{\text {rescue }}$ versus U87 ${ }^{\text {shABL }}$ cells (mRNA: $1.65 \pm 0.03$ fold increase; protein: $0.69 \pm 0.08$ fold increase). The housekeeping gene Beta-2-microglobuline (B2M) was used as internal control in all RT-qPCR analyses, and ACTIN as loading control in all western blots. Results are the mean of at least three independent experiments. Values are expressed as means \pm s.e.m. ns: not significant; ${ }^{*} P<0.05 ; * * P<0.01$. E. Brightfield (top and middle) and phalloidin staining (red; bottom) images of untreated U87, U87 cells exposed to Nilotinib ( $2 \mu \mathrm{M}$; for $72 \mathrm{hrs}$ ), U87 ${ }^{\text {hABL }}$ (shABL-1 and shABL-2), and U87 $7^{\text {rescue }}$ cells. Note that ABL inhibition leads to the acquisition of a fusiform cell shape whereas U87 $7^{\text {rescue }}$ cells exhibit a flatter phenotype. Nuclei stained with DAPI are in blue. Scale bars: $50 \mu \mathrm{m}$. 
Increased ABL mRNA and protein levels were observed in these cells (Figure 1C and 1D). Through these studies, $\mathrm{U} 87^{\text {shABL }}$ refer to stable ABL-mutant cells and U87 $7^{\text {rescue }}$ to U87 ${ }^{\text {shABL }}$ cells transfected with a vector expressing wildtype ABL. Concerning the pharmacological approach, ABL activity assessed by following its phosphorylation on tyrosine residues was impaired using Nilotinib, known to preferentially block ABL at $1-5 \mu \mathrm{M}$ (Supplementary Figure 1B). Intriguingly, we found that $U 87^{\text {shABL }}$ cells adopted a striking morphological change compared to controls, with fewer sites of cell contacts, and a major reorganization of actin filament distribution consistent with a loss of tight junction features (Figure 1E and Supplementary Figure 2A). Consistently, Nilotinib treatment of U87 cells led to a similar phenotype (Figure 1E) and did not further modify the morphology of U87 ${ }^{\text {shABL }}$ cells (Supplementary Figure 1C). Restored ABL levels converted the spindle shape morphology of $U 87^{\text {shABL }}$ cells into a flatter appearance with increased cell contacts in U87 $7^{\text {rescue }}$ cells (Figure 1E).

Although U87 cells exhibit an epithelial morphology (as assessed by ATCC), they express both mesenchymal and epithelial markers. We therefore asked whether the phenotypic modifications caused by ABL inhibition in $U 87^{\text {shABL }}$ cells were accompanied by changes in the expression levels of epithelial and mesenchymal-related genes. U87 $7^{\text {shABL }}$ cells undergo a strong repression of several epithelial markers, such as E-Cadherin, Syndecan-3, Zonal Occludens-1, Cytokeratin-18, and Cytokeratin-19, coinciding with changes in mesenchymal markers: FOX C2, SLUG, TWIST-1 were up-regulated, and SNAILl was down-regulated (Figure 2A-2D and Supplementary Figure $2 \mathrm{~B}$ and $2 \mathrm{C}$ ). Expression levels of epithelial and mesenchymal markers were significantly restored in U87 $7^{\text {rescue }}$ cells (Figure 2A, 2B, and 2D).

To strengthen these results, we next asked whether ABL inhibition could also cause similar morphological and molecular changes in other GBM cell lines with more epithelial characteristics (Supplementary Figure 4). We found that Nilotinib treatment of LN18 and LN229 GBM cells, in which ABL is expressed and constitutively activated, also resulted in the acquisition of a mesenchymal-like morphology (Supplementary Figure S4A and S4B) accompanied by changes in levels of some epithelial (Cytokeratin-18, Syndecan-3, ZEB-1) and mesenchymal (SNAIL, CD44; VIMENTIN as well for LN229 cells) markers (Supplementary Figure S4C$\mathrm{S} 4 \mathrm{~F})$. Thus, ABL impairment in GBM cells enhances both morphological and molecular mesenchymal characteristics.

\section{Increased migration and invasive properties of GBM cells with $A B L$ impairment}

Since ABL knockdown exacerbates the mesenchymal phenotype of U87 cells, we next investigated whether ABL inhibition influences cell motility and invasion. For cell motility, through timelapse videomicroscopy we recorded several parameters: distance, velocity, path of migration, and the duration of motile versus paused behaviour. The migration capacity of $U 87^{\mathrm{shABL}}$ cells was significantly enhanced, with about a 4-fold increase in the average distance travelled and in their mean velocity (Figure 3A-3D and Supplementary Figure 5A-5D). Moreover, whereas control cells paused for $65 \%$ of the time, U87 $7^{\mathrm{shAB}}$ cells spent about $80 \%$ of the time being motile (Figure 3E and Supplementary Figure 5E). The migration capacity of U87 $7^{\text {rescue }}$ cells was drastically reduced compared to that of U87 ${ }^{\text {shABL }}$ cells (Figure 3A-3E). These studies were performed in the presence of $\mathrm{AraC}$ in order to carefully analyse cell motility properties during $20 \mathrm{hrs}$, independently of cell division. However, as AraC can influence cell survival [56], motility studies were also done in the absence of AraC and led to the same results (Supplementary Figure 6A, 6B). Finally, using Matrigel-Boyden chambers to study the cell's invasive capacity, we found that invasiveness of U87 $7^{\mathrm{shABL}}$ cells was increased as compared to that of controls (Supplementary Figure 5F). Taken together, these findings show that the morphological changes caused by ABL impairment in GBM cells are accompanied by enhanced migration and invasion properties.

\section{ABL impairment leads to reduced proliferation and drastically impacts the tumorigenic properties of GBM cells both in vitro and in vivo}

We next investigated whether permanent ABL impairment impacts the cell proliferation capacity by following BrdU incorporation. Quantification analysis revealed a decrease in the percentage of BrdU-positive U87 $7^{\text {shABL }}$ cells compared to controls (Figure 4A). In contrast, no changes were observed in the proportion of apoptotic U87 $7^{\text {shABL }}$ and control cells (Figure 4B and $4 \mathrm{C}$ ). These results prompted us to assess whether and to what extent $\mathrm{ABL}$ inhibition could compromise the tumorigenicity of GBM cells. We performed softagar assays to evaluate the cell's ability to grow in an anchorage-independent manner, a hallmark of cancer cells. We found about $50 \%$ decrease in colony number formed by $\mathrm{U} 87^{\mathrm{shABL}}$ cells compared to controls (Figure 5A, 5B, and Supplementary Figure 7A). Tumorigenic capacity was significantly restored in U87 $7^{\text {rescue }}$ cells (Figure 5A and 5B). Pharmacological inhibition of ABL impacts tumorigenicity of U87, as well as LN18 and LN229 cells, in a dosedependent manner (Figure 5C and Supplementary Figure $7 \mathrm{~B}$ and $7 \mathrm{C}$ ), pointing to a requirement for $\mathrm{ABL}$ in the oncogenic program of GBM cells we tested. We next performed xenograft studies and found that U87 $7^{\text {shABL }}$ cells fail to develop tumour masses in contrast to controls (Figure 5D). Together, these results provide evidence that 

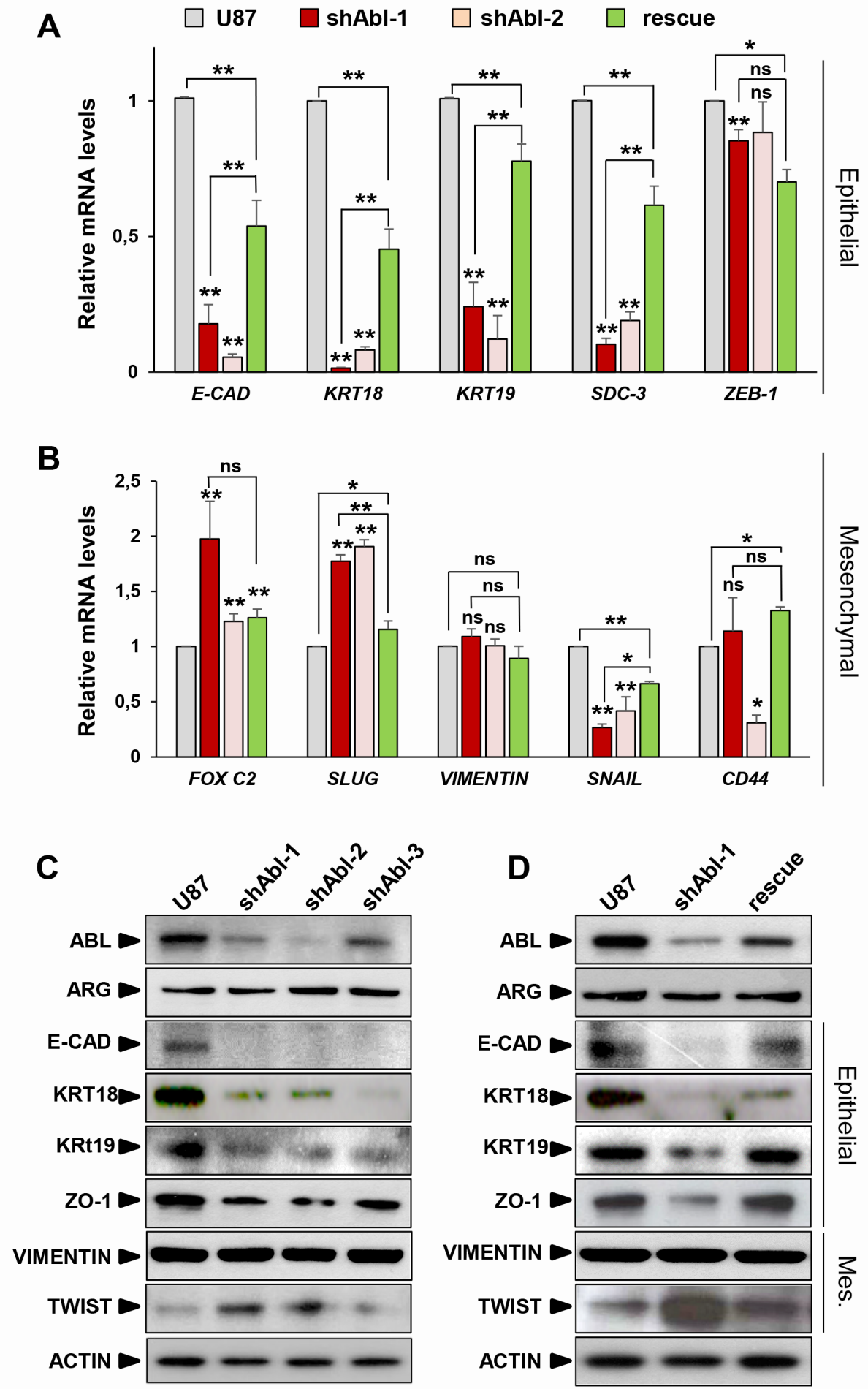

Figure 2: ABL impairment increases mesenchymal molecular traits at the expense of epithelial markers. (A, B) RT-qPCR analysis showing repression of the epithelial markers (A), such as E-Cadherin (E-CAD), Cytokeratin-18 (KRT18), Cytokeratin-19 (KRT19), Syndecan-3 (SDC-3), and ZEB-1. Concerning mesenchymal markers (B), FOX C2 and SLUG, but not VIMENTIN, are up-regulated in U87 $7^{\text {shABL }}$ cells compared to controls. Note down-regulation of $S N A I L$ levels in U87 $7^{\text {shABL }}$ cells. Levels of $C D 44$, which is considered as a marker of mesenchymal or stemness traits depending on the culture conditions, are also reported. Quantitative analysis in U87 rescue cells shows significant increase of all epithelial markers accompanied by a decreased expression of FOX C2 and SLUG mesenchymal markers. C, D. Western blots showing decrease in the expression levels of E-Cadherin (E-CAD), Cytokeratin-18 (KRT18), Cytokeratin-19 (KRT19), Zonal Occludens-1 (ZO-1), and increase of TWIST-1 (TWIST) in U87 $7^{\text {shABL }}$ compared to controls (C). Restoration of E-CAD, KRT18 (although only partial), KRT19, and ZO-1 levels together with a decrease in TWIST levels were observed in U87 $7^{\text {rescue }}$ cells (D). Mes: Mesenchymal. Results are the mean of three independent experiments. Values are expressed as means \pm s.e.m. ns: not significant; $* P<$ $0.05 ; * * P<0.01$. 
A
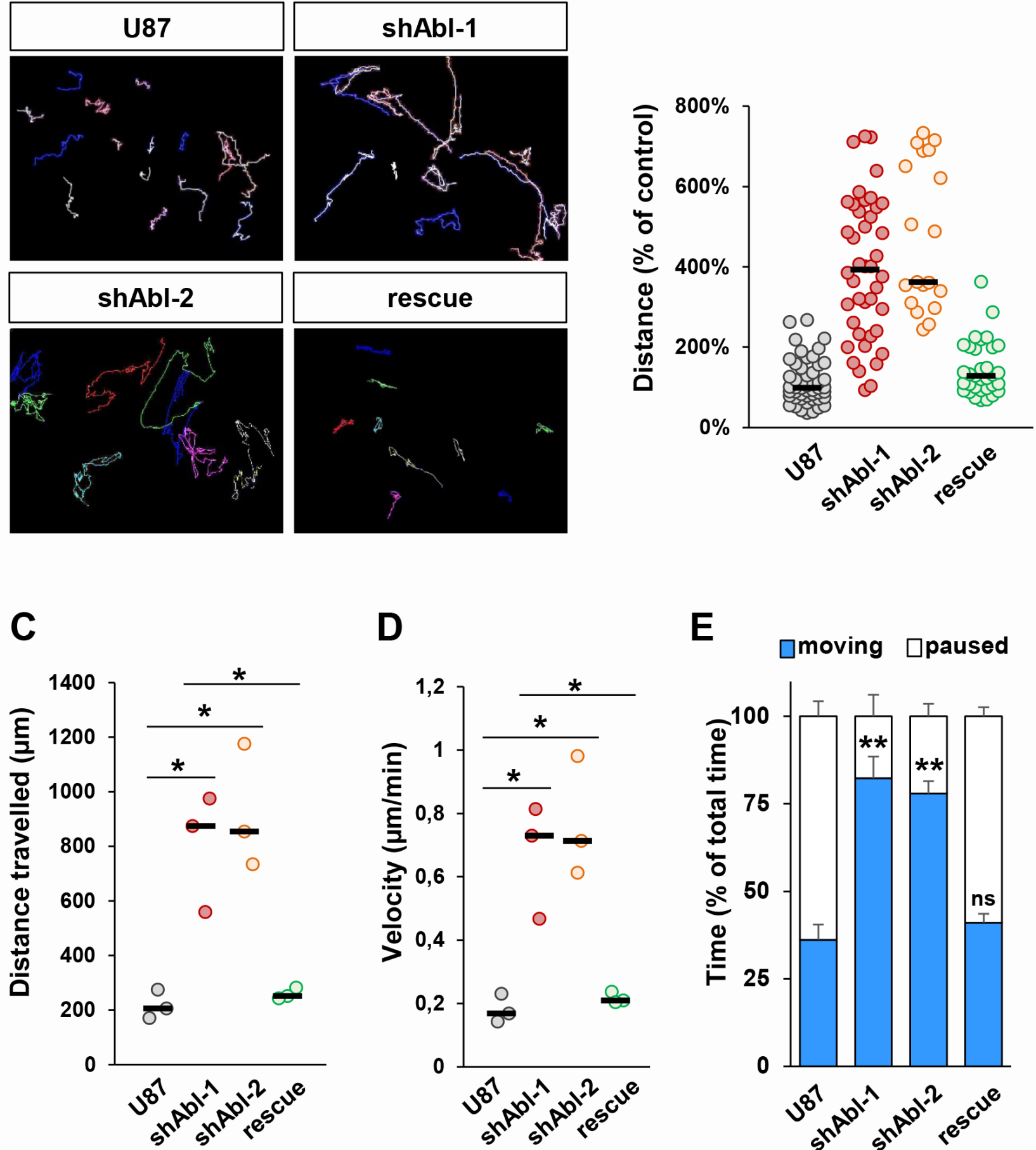

D

$\mathbf{E}$
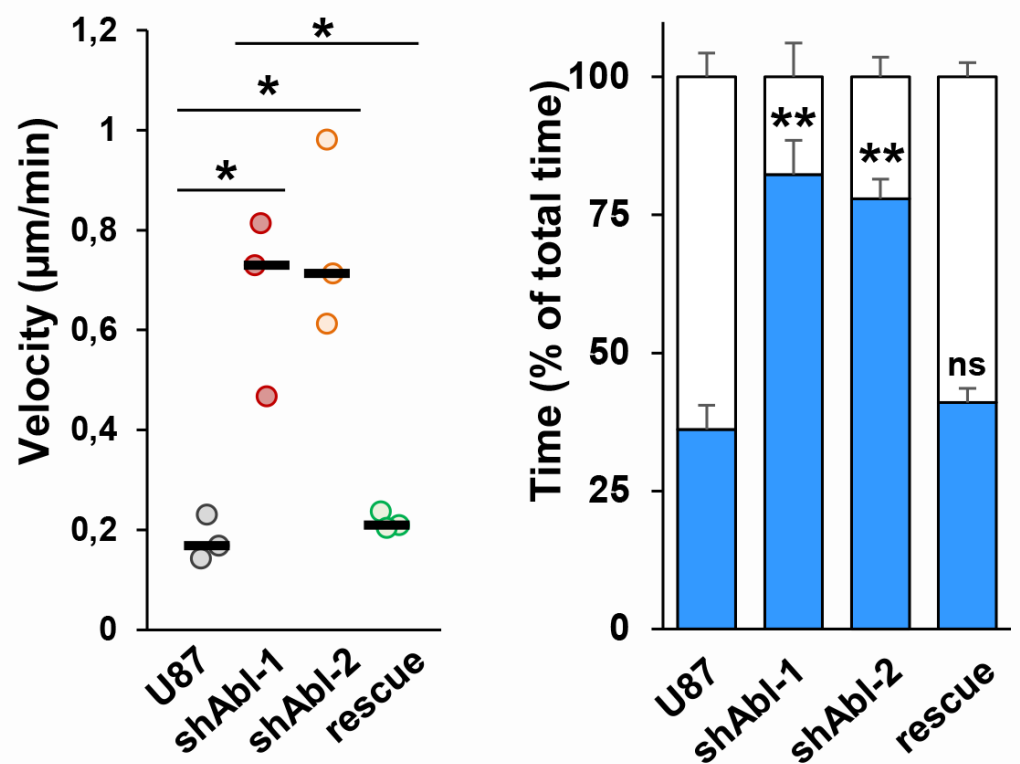

Figure 3: Increased migration properties of U87 cells with impaired ABL. A. Representative images of migration paths of U87, U87 $7^{\text {shABL}}$, and U87 $7^{\text {rescue }}$ cells analysed by time-lapse videomicroscopy $(n=3)$. B-E. Quantification of time-lapse videomicroscopy showing the distance the cells travelled expressed as percentage of the distance travelled by control cells (B, each dot represents a single cell analysed), the total distance the cells travelled $(\mathbf{C}$, each dot represents the mean of independent experiments; U87: $206.4 \mu \mathrm{m} \pm 30.5 \mu \mathrm{m}$; shABL-1: $874.1 \mu \mathrm{m} \pm 125.3 \mu \mathrm{m}$; shABL-2: $854.2 \mu \mathrm{m} \pm 131.7 \mu \mathrm{m}$; rescue: $251.7 \mu \mathrm{m} \pm 12.1 \mu \mathrm{m}$ ), the mean velocity of the cells during the $20 \mathrm{hrs}$ of recording (D, each dot represents the mean of independent experiments; U87: $0.17 \pm 0.02 \mu \mathrm{m} / \mathrm{min}$; shABL-1: 0.73 $\pm 0.1 \mu \mathrm{m} / \mathrm{min}$; shABL-2: $0.71 \pm 0.11 \mu \mathrm{m} / \mathrm{min}$; rescue: $0.21 \pm 0.01 \mu \mathrm{m} / \mathrm{min}$ ), and the time percentage the cells spent moving versus paused (E). Values are expressed as means \pm s.e.m. ns: not significant; $* P<0.05 ; * * P<0.01$. 
intact $\mathrm{ABL}$ confers tumorigenicity to GBM cells.

\section{ABL knock-down affects self-renewal capability of GBM cells}

We next asked whether the loss of tumorigenicity of $\mathrm{U} 87^{\text {shABL }}$ cells is at least partially due to a modification in their tumour initiating properties. Pseudo-sphere formation assays (also called neurosphere assays) were performed in stem cell-permissive media to examine the U87 cell selfrenewal capacity [57]. We found that the total number of spheres derived from U87 $7^{\text {shABL }}$ cells is significantly reduced compared to controls (Figure 6A-6C). Similar results were observed by pharmacological $\mathrm{ABL}$ inhibition with Nilotinib (Figure 6B). The self-renewal capability
A
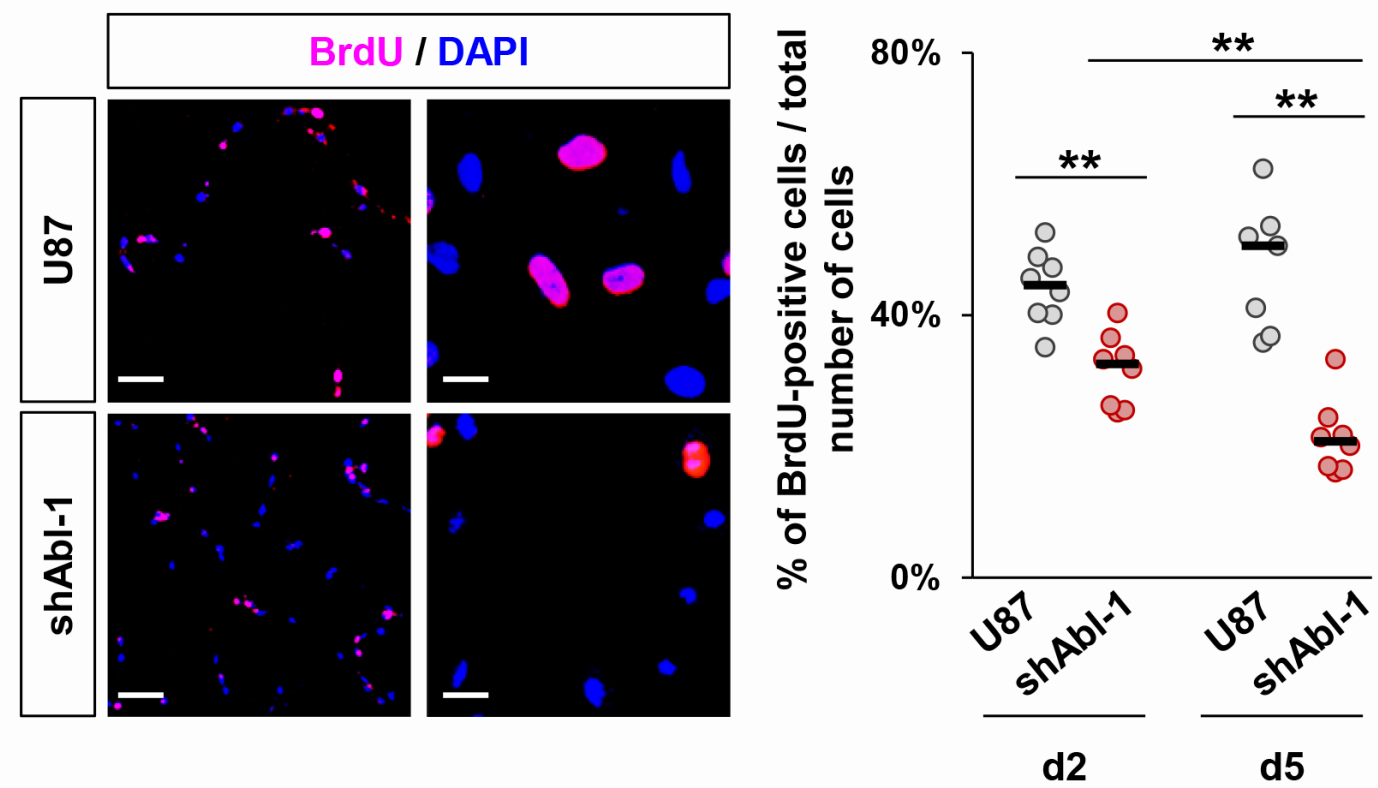

B

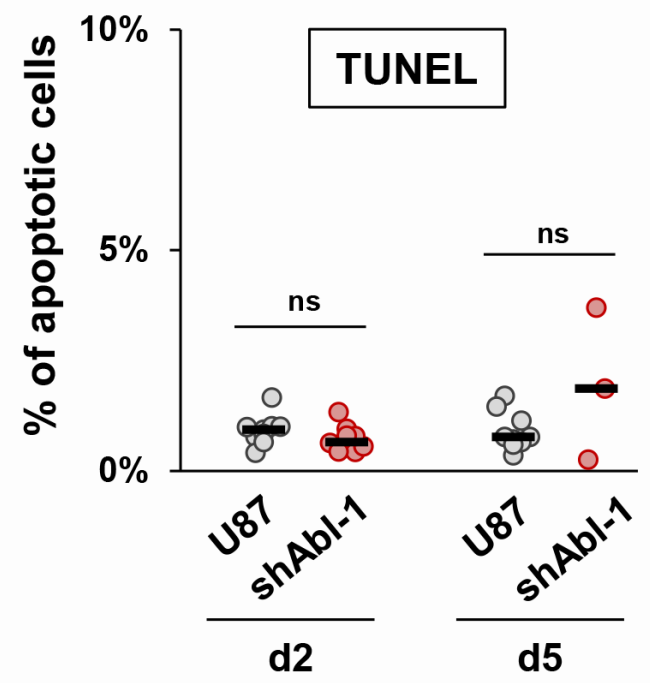

C

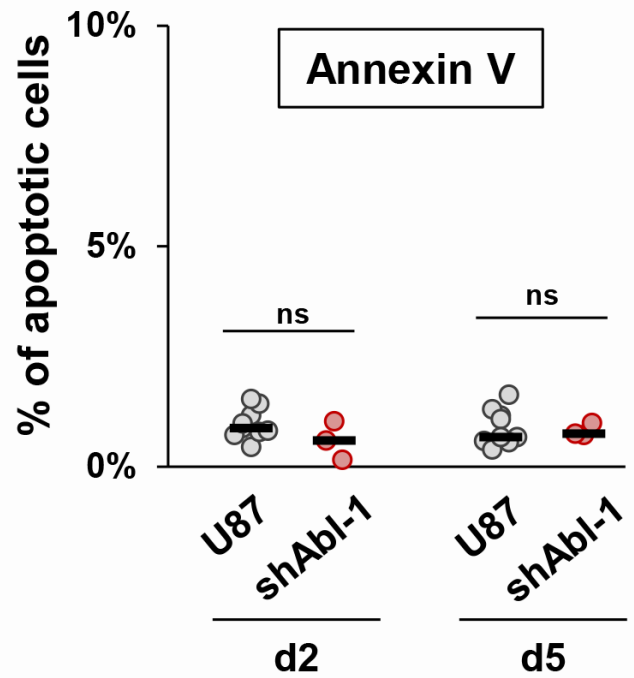

Figure 4: ABL inhibition decreases cell proliferation without affecting cell survival. A. Representative images (left) and quantification (right) of cell proliferation determined by analysis of BrdU incorporation. The proliferation rate of U87 $7^{\text {shABL }}$ cells is reduced

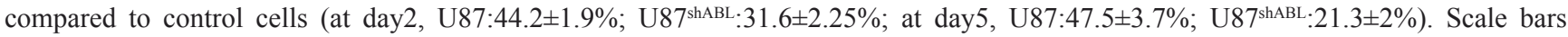
correspond to $250 \mu \mathrm{m}$ (left) and $50 \mu \mathrm{m}$ (right). B, C. Quantitative analysis of apoptotic cells as assessed by either TUNEL (B) or Annexin $\mathrm{V}$ expression $(\mathbf{C})$ in $\mathrm{U} 87$ and $\mathrm{U} 87^{\mathrm{sh} A B L}$ cells. Each dot represents the mean of independent experiments. ns: not significant; $* * P<0.01$. 

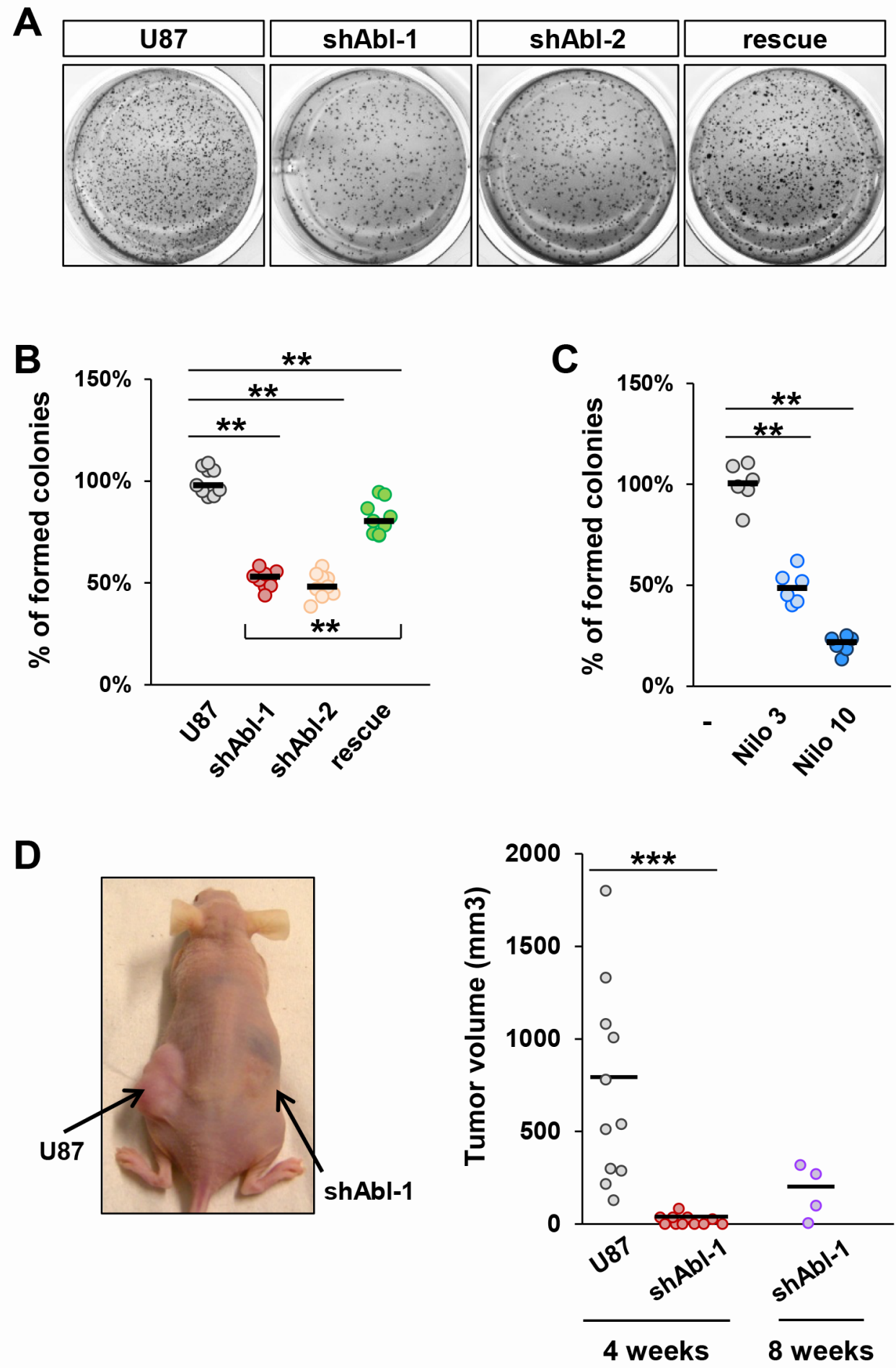

Figure 5: Tumorigenic properties of U87 cells are impaired by ABL inactivation both in vitro and in vivo. A-C. Anchorageindependent growth assay showing reduced in vitro tumorigenic properties of U87 ${ }^{\text {shABL }}$ (shABL-1: $52.05 \pm 2.1 \%$; shABL-2: 48.9 $\pm 2.2 \%$ ) and partial restoration in U87 $7^{\text {rescue }}$ cells (A and $\mathbf{B} ; 81.8 \pm 2.3 \%$;). Reduced tumorigenic properties of Nilotinib-treated U87 cells compared to controls (C; $3 \mu \mathrm{M}$ : $49.2 \pm 3.3 \% ; 10 \mu \mathrm{M}: 20.7 \pm 1.7 \%)$. Each dot represents the mean of independent experiments. D. Xenograft studies were performed by subcutaneous injection of U87 (left flank) and U87 $7^{\text {shABL }}$ (right flank) cells. A representative mouse 4 weeks after injection is shown (left panel). Quantitative analysis of the volume of dissected tumours 4 and 8 weeks after cell injection (right panel). Note that after 4 weeks, U87 cells formed in all injected mice tumours of an average volume of $\sim 720 \mathrm{~mm}^{3}$, whereas U87 ${ }^{\text {shABL }}$ cells exhibited a drastically reduced capacity to form tumours (mean tumour volume: $\sim 20 \mathrm{~mm}^{3}$ ), which were detected in only $54 \%$ of injected mice. After 8 weeks, the mean of tumour volume generated by $\mathrm{U} 87^{\mathrm{shABL}}$ cells was $\sim 170 \mathrm{~mm}^{3}$. Each dot corresponds to the tumour value of one mouse. $* * P<0.01$; $* * * P<0.001$. 
A

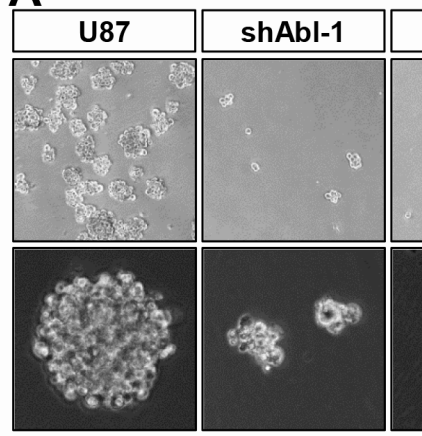

C

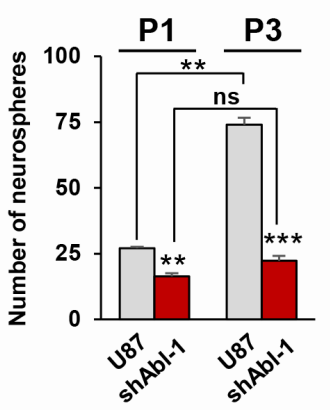

\section{\begin{tabular}{l|l|l|l|l} 
shAbl-2 & rescue \\
\hline
\end{tabular}}

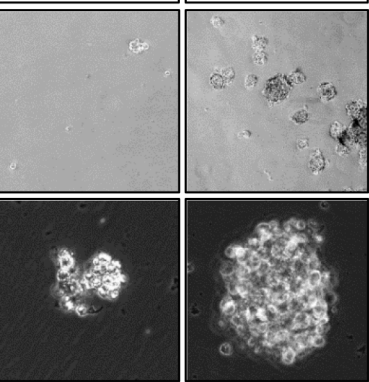

B

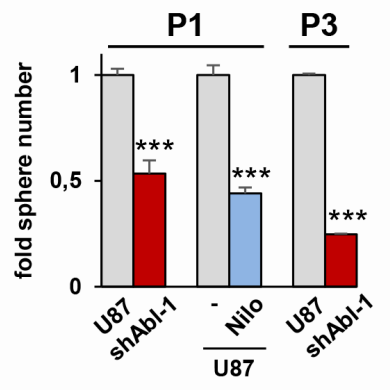

D

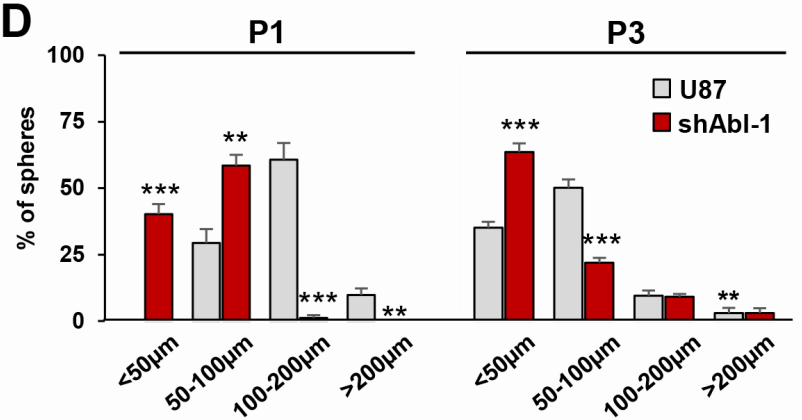

E

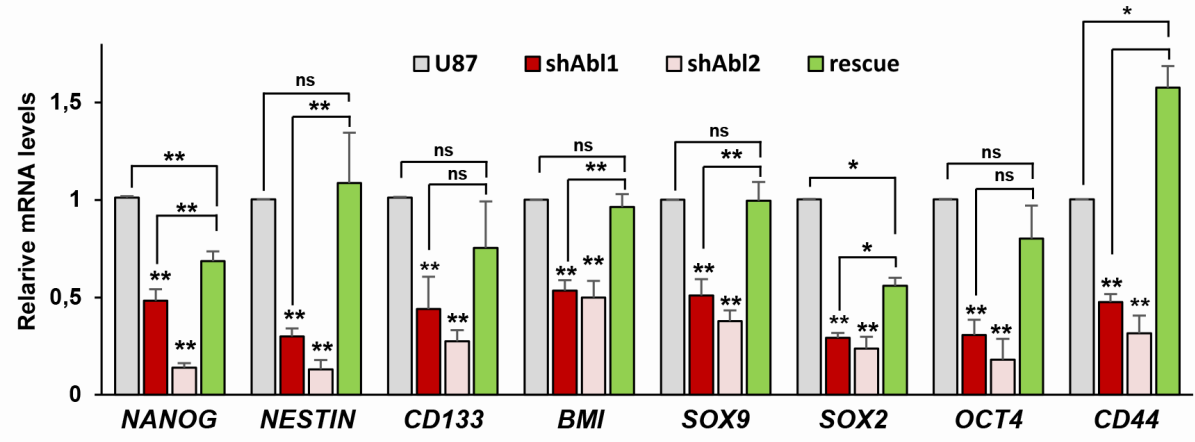

$\mathbf{F}$
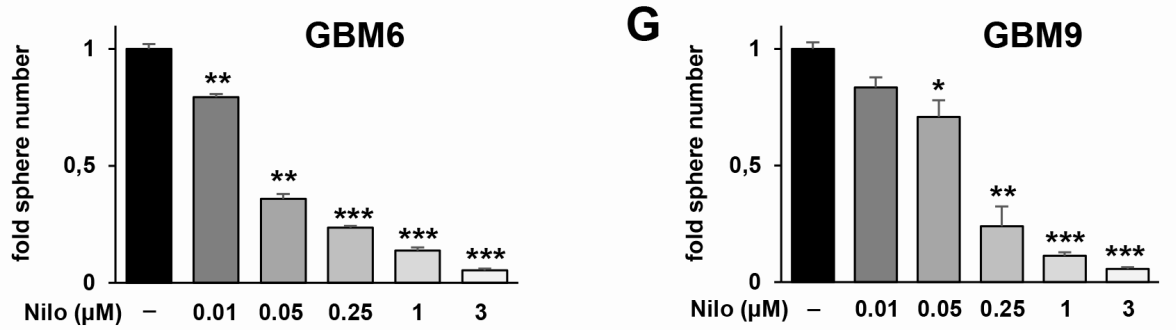

Figure 6: Permanent ABL inhibition interferes with neurosphere formation and expression of self-renewal markers in GBM cells. A. Representative images of spheres derived from U87, U87 $7^{\mathrm{shBL}}$, and U87 $7^{\text {rescue }}$ cells. B, C. Reduced numbers of spheres

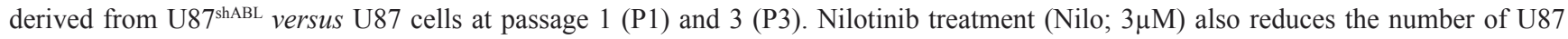
spheres at P1. In B, results are expressed as fold changes in sphere numbers between cells with ABL inhibition versus controls. In C, results are expressed in terms of number of formed spheres compared to the number of seeded cells. This way of reporting data determines the sphere forming efficiency of each cell line, emphasizing differences in self-renewal capacity. Note that as the number of passages increases (from P1 to P3), the sphere forming efficiency of U87 cells raises up (2.7 fold), whereas the capacity of U87 $7^{\text {shABL }}$ cells does not significantly change. D. Size of spheres derived from U87 and U87 ${ }^{\text {shABL }}$ cells analysed after P1 and P3. E. RT-qPCR analyses showing the repression of pluripotent markers (NANOG, NESTIN, CD133, BMI, SOX9, SOX2, OCT4, and CD44) in U87 $7^{\text {shABL }}$ compared to U87 spheres. Partial restoration of most of the stemness markers was observed in U87 rescue cells. Data correspond to biological triplicates. F, G. GBM6 (F) and GBM9 $(\mathbf{G})$ cells in neurosphere conditions were exposed to various doses of Nilotinib $(\mu \mathrm{M})$. Sphere numbers were quantified after 14 days of culture. Each experiment was done in triplicate. Values are expressed as means \pm s.e.m. ns: not significant; $* P<0.05 ; * * P<0.01 ; * * *$ $P<0.001$. 


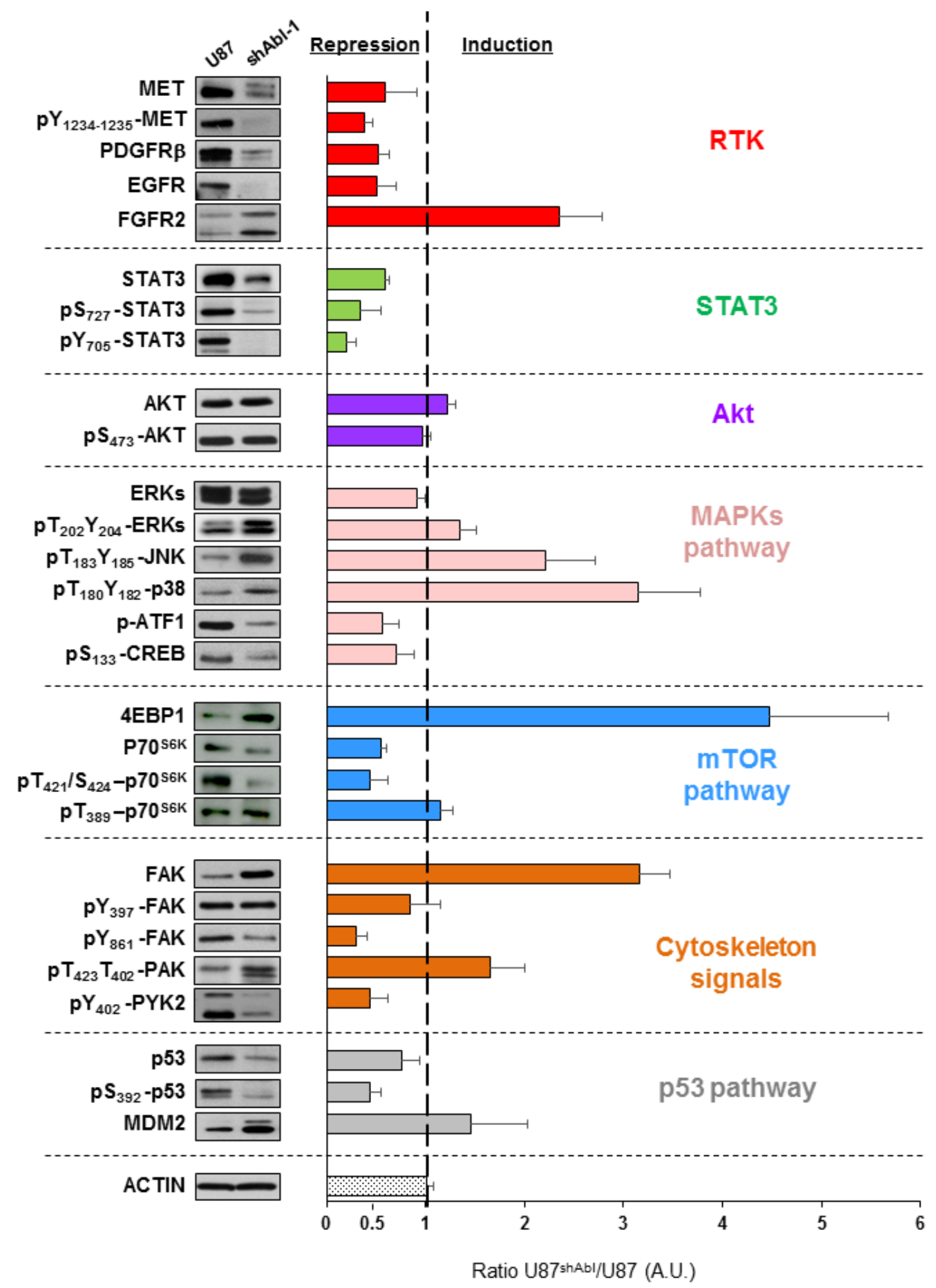

Figure 7: ABL down-regulation modifies multiple signalling components in GBM cells. Western blots showing the expression and phosphorylation levels of RTKs (MET, $\mathrm{pY}_{1234-1235^{-}}$-MET, PDGFR $\beta$, EGFR, FGFR2), AKT (AKT, $\mathrm{pS}_{473}{ }^{-}$AKT), STAT3 (STAT3, $\mathrm{pS}_{727^{-}}$ STAT3, $\mathrm{pY}_{705}$-STAT3), MAPKs pathway (ERKs, $\mathrm{pT}_{202} \mathrm{Y}_{204}$-ERKs, $\mathrm{pT}_{183} \mathrm{Y}_{185}-\mathrm{JNK}, \mathrm{pT}_{180} \mathrm{Y}_{182}$-p38, p-ATF1, $\mathrm{pS}_{133}$ CREB), mTOR pathway

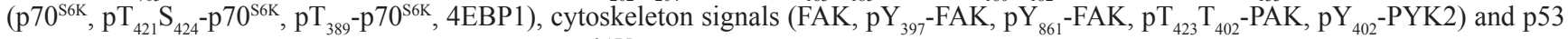
pathway ( $\left.\mathrm{p} 53, \mathrm{pS}_{392}-\mathrm{p} 53, \mathrm{MDM} 2\right)$ in U87 and U87 $7^{\mathrm{shABL}}$ cells. Representative western blots are shown on the left. The graph on the right shows the ratio of expression or phosphorylation levels of the indicated proteins in U87 $7^{\text {shABL }}$ versus U87 cells (quantification from three independent experiments). A.U: Arbitrary units. Values are expressed as means \pm s.e.m. 
of U87 $7^{\text {shABL }}$ cells was next examined after dissociation of primary spheres and low-density replating to form secondary spheres. At passage 3, the overall number of spheres generated from U87 $7^{\text {shABL }}$ cells is more than threefold reduced compared to controls (Figure 6B-6D). Since the same number of cells were seeded in all conditions, we were able to assess the sphere forming efficiency of both cell lines overtime. Data show that, as the number of passages increases (from P1 to P3), the sphere forming efficiency of U87 cells raises up (2.7 fold), whereas the capacity of $U 87^{\text {shABL }}$ cells does not significantly change (Figure 6C). Moreover, a detailed analysis at passage 1 and 3 showed that the majority of spheres derived from U87 $7^{\text {shABL }}$ cells are smaller than $100 \mu \mathrm{m}$ (Figure 6D).

To identify the molecular changes underlying the reduced self-renewal capacity resulting from ABL impairment, we analysed the expression levels of several stem cell markers and found that $N A N O G$, NESTIN, CD133, BMI, SOX9, SOX2, OCT4, and CD44 (considered to be a marker of mesenchymal stem cells) were significantly downregulated in spheres derived from U87 $7^{\text {shABL }}$ cells compared to controls (Figure 6E and Supplementary Figure 8B). Restoration of ABL levels led to a raise in number and size of spheres as well as expression levels of most stem cell markers in U87 $7^{\text {rescue }}$ spheres (Figure 6A and 6E). Altogether, these results indicate that permanent $\mathrm{ABL}$ inhibition interferes with the expression of stemness markers and with sphere formation capacity of U87 cells.

We further investigated whether ABL targeting also affects stem cell-like properties in human primary GBM cells. We used GBM6 and GBM9 stem-like cells with different molecular and biological properties, capable of self-renewing and generating infiltrative tumours after grafting into nude mice $[58,59]$. Nilotinib treatment prevented the GBM neurosphere formation in a dosedependent manner (Figure 6F and 6G). Notably, Nilotinib impairs self-renewal capacity of GBM6 and GBM9 cells at lower doses as compared to U87 cells (around 100fold less), a remarkable effect considering that stem cells, thought to be responsible of tumour recurrence, are known to be resistant to several drugs. Collectively, these results highlight that intact $\mathrm{ABL}$ is required to maintain stem-cell like properties in the GBM cells we tested.

\section{Permanent ABL inhibition causes a drastic change in the signalling network components of GBM cells}

The severe impact on the tumorigenic and selfrenewal properties of GBM cells with impaired ABL function can be interpreted at least in two ways. One scenario could be that ABL participates in the oncogenic program by ensuring the activation of one key signalling component (or a small number of them): its inhibition would therefore interfere with the oncogenic execution of upstream regulators by altering a key modulator. Alternatively, ABL might act as a coordinator of the overall signalling threshold: its inhibition would therefore impact the oncogenic program as the signalling machinery is disrupted at multiple points. To discriminate between these two possibilities, we analysed the expression and phosphorylation levels of several signals known to regulate the tumorigenic and self-renewal properties of GBM cells. Remarkably, we found a drastic alteration of multiple RTKs and intracellular signals in U87 $7^{\mathrm{shABL}}$ cells compared to controls. These changes include: a) loss of MET, PDGFR $\beta$ and EGFR expression, and of MET phosphorylation; b) down-regulation of the

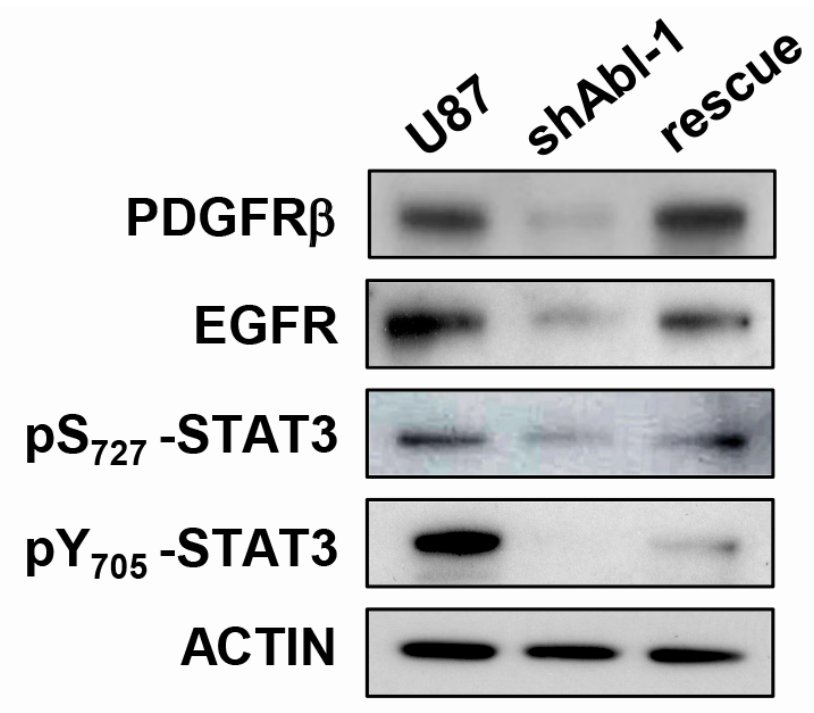

Figure 8: Signalling status in GBM cells is sensitive to ABL threshold. Western blots showing expression levels of PDGFR $\beta$ and EGFR as well as the phosphorylation status of $\mathrm{pS}_{727}-\mathrm{STAT3}, \mathrm{pY}_{705}-\mathrm{STAT3}$ in U87, U87 ${ }^{\text {shABL }}$, and U87 ${ }^{\text {rescue }}$ cells. 
phosphorylation levels of STAT3, ATF-1, CREB, and p $\left.70^{\mathrm{S} 6 \mathrm{~K}} ; \mathrm{c}\right)$ changes in $\mathrm{p} 53$ expression and phosphorylation on $\mathrm{Ser}_{392}$ that confers transcriptional competence towards specific targets [9, 20] (Figure 7). Interestingly, expression and phosphorylation levels of some signalling molecules, such as PDGFR $\beta$, EGFR, $\mathrm{pS}_{727}$-STAT3, and $\mathrm{pY}_{705}$-STAT3, are either totally or partially restored in U87 $7^{\text {rescue }}$ cells (Figure 8). Together, these results indicate that $\mathrm{ABL}$ acts as a signalling coordinator by ensuring the expression and/ or phosphorylation levels of multiple components known to participate to the tumorigenic properties of GBM cells.

\section{DISCUSSION}

The effect of Imatinib on cancer cells including GBM has been mainly attributed to PDGFR inhibition $[45,50,60]$, although it also targets ABL and KIT. Interpreting the Imatinib effects on GBM cells is further confounded by the existence of a regulatory feedback loop in which ABL and PDGFR reciprocally regulate their phosphorylation levels [47]. Our studies highlight that permanent ABL inhibition in GBM cells leads to profound changes at molecular and biological levels: the mesenchymal features of GBM cells are exacerbated as shown by loss of epithelial-like polarity, increased migration and invasion capacity, whereas proliferation and tumorigenesis are compromised (Figure 9). Our studies uncover an additional feature of $\mathrm{ABL}$ only reported so far in CML: the regulation of stem-cell like properties. This is supported by our observation that ABL inhibition down-regulates expression of stem-cell markers in spherecultured conditions and prevents neurosphere formation (Figure 9). Collectively, these studies support the notion that the oncogenic role of ABL in solid tumours, like GBM, relies on its capability to coordinate a signalling setting that determines cell tumorigenicity and stem-cell like properties.

\section{ABL coordinates multiple biological properties in GBM cells}

The present study extends previous reports on persistent ABL inhibition in cancer cells [61] and reveals dramatic molecular and behavioural consequences of permanent ABL impairment overtime. The enhanced mesenchymal traits conferred by ABL targeting in GBM cells impact their biological properties as illustrated by increased migration/invasion. This is consistent with molecular changes occurring in cells with impaired ABL: down-regulation of epithelial markers (such as E-Cadherin, ZO-1, Cytokeratin-18, Cytokeratin-19, Syndecan-3, and ZEB-1 to a lesser extent) and upregulation of mesenchymal markers (such as $F O X C 2$, SLUG, and TWIST-1). The acquisition of molecular and morphological traits by targeting ABL appears to be a dynamical process as some changes are already observed within 48 hrs of ABL inhibition (Supplementary Figure 9A-9C), which is further supported by the reversion of these traits when ABL expression levels are restored. The competence of ABL to influence epithelial/ mesenchymal features is corroborated by the acquisition of mesenchymal-like morphology of epithelial-like GBM cells such as LN18 and LN229. Remarkably, the proliferation and the tumorigenicity of GBM cells are compromised when $\mathrm{ABL}$ is impaired. In contrast to our findings, it has been shown that increased expression and activation levels of ABL and ARG lead to enhanced motility and invasive properties of breast cancer cells [1, $3,16,62,63]$. This is coherent with their engagement in the actin polymerisation machinery, which leads to the formation of membrane protrusions, morphological changes, and affects cell adhesion and migration [23]. Among putative signals conferring enhanced motility in GBM cells with permanent ABL targeting, ARG could be implicated also taking into account its reported localisation in invadopodia (actin-rich structures) and its involvement in extracellular matrix degradation and invasion [63, 64]. Nevertheless, the overall signalling resetting we report in cells with permanent $\mathrm{ABL}$ impairment could underlie the involvement of other regulators of cell motility/invasion.

Changes in GBM cell behaviour are most likely caused by the drastic alterations of signalling components we highlighted. Permanent ABL impairment leads to down-regulation in the levels of PDGFR/EGFR expression as well as of MET expression/phosphorylation, reinforcing the existence of a feedback loop between ABL and RTKs [26, 47]. Such down-regulation of RTKs could be per se incompatible with the tumorigenic competence of GBM cells [45, 65-67]. Consistently, drugs targeting several RTKs at the same time elicit efficient responses on a range of GBM cells $[45,50,54]$. Besides RTKs, we show a severe alteration also of MAPKs, STAT3, and p53 intracellular pathways, each of them being able to contribute to GBM tumorigenicity $[68,69,70]$. In our opinion, such signalling resetting likely reflects direct effects of reduced $\mathrm{ABL}$ inputs for some signals (known as ABL effectors) and indirect consequences of ABL impairment overtime for others. Collectively, this resetting implies that $\mathrm{ABL}$ acts as a signalling coordinator by (directly or indirectly) ensuring the expression and/or phosphorylation levels of multiple components known to participate to the tumorigenic properties of GBM cells. An intriguing question we also addressed is to which extent the overall changes occurring in cells with ABL impairment are reversible. The U87 $7^{\text {rescue }}$ cells with restored $\mathrm{ABL}$ levels have been instrumental not only to rule out off-target effects of the shRNA approach, but also to demonstrate that signalling, molecular, and biological features of ABL-targeted cells are reversible. Such reversibility underlines a remarkable plasticity of GBM cells to ABL threshold. 
Uncoupling mesenchymal from stem-cell like features in GBM cells by targeting $A B L$

Cancer cells can de-differentiate through aberrant activation of epithelial-mesenchymal transition thereby increasing cancer cell motility and dissemination, but also promoting their self-renewal capability [71]. The direct link between mesenchymal features and stemness has been supported by several studies showing that activators of the epithelial-mesenchymal transition (such as TWIST1, SNAIL1, SLUG, ZEB1) also confer stemness properties [72-74]. However, an exception to this widely accepted concept has been reported. It is the

\section{Cells with permanent Abl impairment}

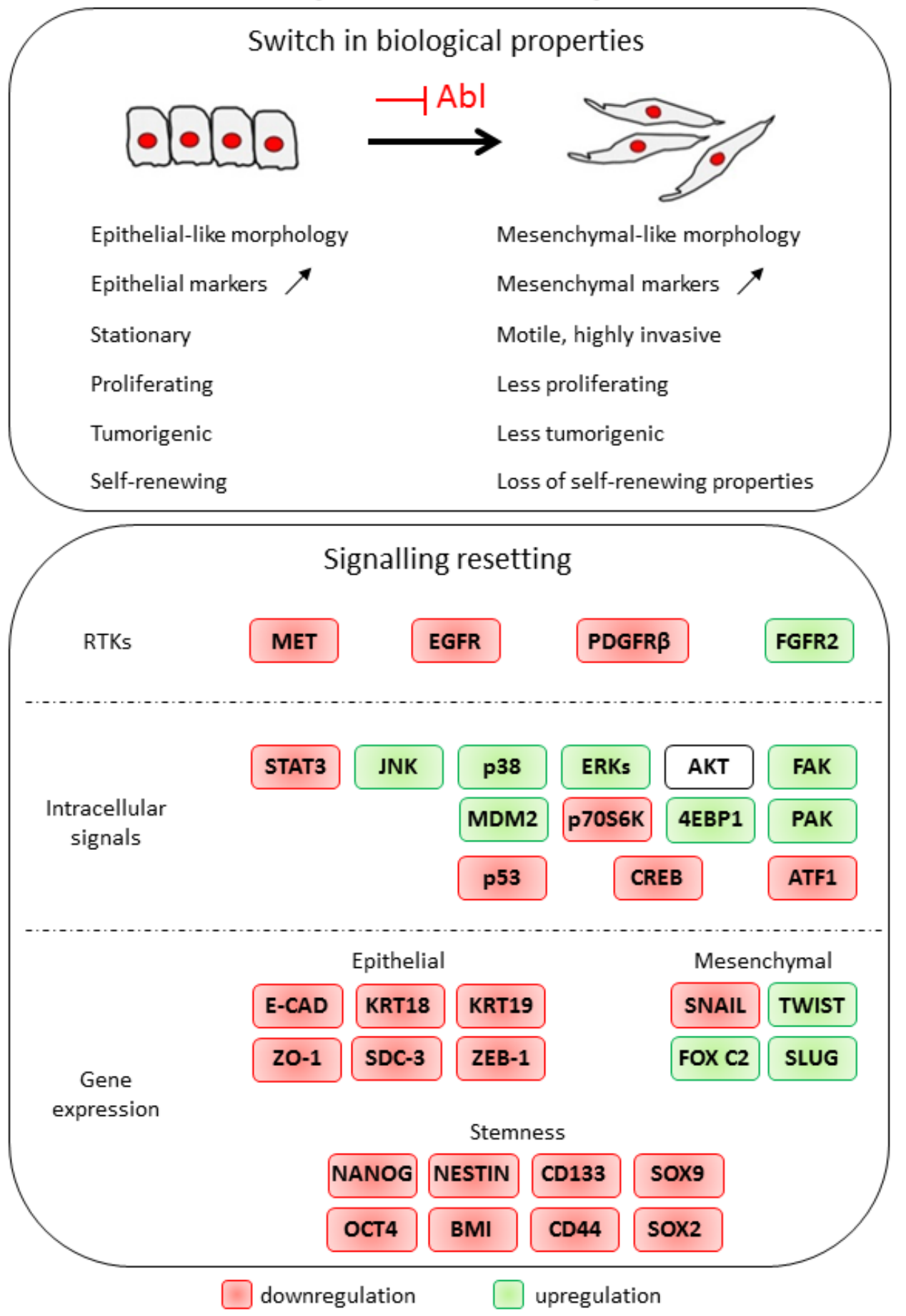

Figure 9: Permanent Abl ablation in GBM cells leads to a switch in biological properties and to a signalling resetting. 
case of PRRX1, an activator of epithelial-mesenchymal transition that nevertheless suppresses stemness traits [75]. In particular, PRRX is coexpressed and cooperates with TWIST1 in favouring cell migration and invasion while depleting stemness properties [75]. The biological and mechanistic outcomes from these studies highlight the possibility of uncoupling stemness from mesenchymal traits in cancer cells [76]. Such a new concept has recently been supported by an elegant study based on a breast model of tumorigenesis in which epithelial-mesenchymal regulators have not been genetically modified. The authors have shown that the epithelial-mesenchymal plasticity occurring in metastatic process appears to be irrelevant for differential stemness capacity [77]. Our studies provide an additional example of uncoupling mesenchymal and stem-like features. Indeed, the enhanced mesenchymal properties in GBM cells with ABL ablation is paralleled by the loss of stem cell markers, such as $N A N O G$, NESTIN, CD133, BMI, SOX9, SOX2, and OCT4, and reduced neurosphere formation. Moreover, our cellular system demonstrates a remarkable plasticity of epithelial/ mesenchymal versus stemness traits according to $\mathrm{ABL}$ thresholds (by comparing U87, U87 ${ }^{\text {shAbl }}$, and U87 $7^{\text {rescue }}$ cells). To our knowledge, this is the first example linking ABL to stem-cell like properties in solid tumours, compatible with haematopoietic stem cell renewal by BCR-ABL in CML [78, 79]. Such modulation of stem cell-like properties may offer an additional mechanism to contrast GBM tumorigenicity in cells that make use of ABL to exacerbate stemness maintenance. Future studies will determine whether the uncoupling of mesenchymal and stem-cell like features with ABL inhibition also occurs in other cells derived from solid tumour, particularly those in which ABL has been reported to elicit functional responses. How ABL may impact stemness is an intriguing question that deserves several biochemical and molecular screens performed in a panel of cells. It is tempting to speculate that reduced stemness in GBM cells lacking ABL is likely due to the alteration of multiple components, including receptors of extracellular signals and intracellular effectors.

\section{Could ABL be a target for GBM therapies?}

The drastic consequence of targeting ABL in GBM cells like those used in our study solicits the question of whether ABL antagonists can be relevant in therapy. This possibility is supported by our findings showing that permanent $\mathrm{ABL}$ ablation causes a dramatic change in the expression/activation levels of multiple signals relevant in GBM biology. Furthermore, as ABL inhibition impinges also on stemness properties of GBM cells, it will be important to assess whether cancer stem cells become more sensitive to chemotherapeutic agents or radiotherapy. Although some clinical trials have not shown any beneficial effects of targeting ABL for GBM treatment [48,
$60,80]$, additional trials using ABL inhibitors are currently ongoing (e.g. http://clinicaltrials.gov/show/NCT01140568; https://www.klinikum.uni-heidelberg.de/Recurrentglioblastoma-WHO-grade-IV.108973.0.html?\&L=\%20 1). An easy conclusion from failure of completed trials is that while $\mathrm{ABL}$ antagonists are highly effective on $\mathrm{CML}$ cells addicted to the BCR-ABL oncogenic form, they elicit moderate response on cells in which the oncogenic contribution of not mutated ABL can be substituted by other signals. However, an alternative possibility is that we still do not know how to use ABL antagonists for GBM therapy. Examining beneficial (and limiting) effects of ABL inhibition for GBM treatment is conditioned by at least two main issues. First, the combined drug(s) to use for therapies is likely to determine the extent of success (or failure). However, determining which combinations maximize effectiveness among the limitless possibilities remains a major challenge. A strategy worth to explore could be to exacerbate the effects of ABL inhibition with agents eliciting cytotoxic effects [81, 82]. Second, the identification of a molecular signature would permit targeting of a GBM patient subgroup sensitive to ABL inhibitors. In this respect, previous studies identified candidate markers predicting the sensitivity of solid tumours to ABL inhibitors [20, 34, 83].

How can signatures of GBM patients sensitive to ABL antagonists be identified? It is tempting to speculate that $\mathrm{ABL}$ expression levels might not be the appropriate criteria to use, since $\mathrm{ABL}$ requirement is most likely determined by the oncogenic cascade operating in GBM. One possibility is to use a set of changes caused by $\mathrm{ABL}$ inhibition, such as those we highlight in this study, to define a "molecular code". This code can then be used to search for putative patient subgroup(s) by bioinformatically revisiting GBM (epi)genomic databases. Such studies could also predict convergent and compensatory pathways in order to design optimal combined drug treatments. Nevertheless, we also propose to carefully take into account that the drastic molecular and biological effects of ABL inhibition in GBM cells are reversible, at least to a certain extent, once $\mathrm{ABL}$ threshold is restored. Addressing this issue will provide insights on whether constant treatment of GBM patients with ABL antagonists may be required to convert GBM malignancy into a stable chronic disease and/or whether Abl targeting therapies can only be effective when combined with cytotoxic agents.

\section{CONCLUSIONS}

Overall our data support the concept that the oncogenic role of $\mathrm{ABL}$ in solid tumours relies on its capability to coordinate a signalling setting that determines tumorigenic and stem-cell like properties. Thus, our findings together with those from other studies reinforce the potential of treating solid tumours with 
ABL antagonists, most likely in combinatorial therapies. We believe that efficient ABL targeted therapies are conditioned by the identification of molecular signatures to delineate responding patients and by the assessment of whether ABL drug may convert a malignant into a stable chronic disease.

\section{MATERIALS AND METHODS}

\section{Cell culture and compound treatment}

Human U87-MG (U87), LN18, and LN229 cell lines were obtained from ATCC collection. The generation of human GBM6 and GBM9 cells derived from GBM patients has been previously described [58]. The U87 cell line was cultured in RPMI-1640 (Invitrogen Life Technologies) whereas the LN18 and LN229 cells were grown in Dulbecco's modified Eagle's media (DMEM; Invitrogen Life Technologies). Both media were supplemented with $10 \%(\mathrm{v} / \mathrm{v})$ foetal bovine serum (FBS), 100U/mL penicillin, $100 \mu \mathrm{g} / \mathrm{mL}$ streptomycin, $4 \mathrm{mM}$ L-glutamine, and $1 \mathrm{mM}$ of sodium pyruvate (defined as complete media). Cells were grown at $37^{\circ} \mathrm{C}$ in a humidified atmosphere of $5 \% \mathrm{CO}_{2}$ and the medium was changed every 2-3 days. GBM6 and GBM9 cells were cultured in stem-cell permissive medium as previously reported [58]. Cells were cultured for $24 \mathrm{~h}$ prior to Nilotinib treatment (Selleckchem; the time of treatment is indicated in figure legends).

\section{Cell transfection}

For cell transfection, the following plasmids carrying shRNA sequences were used: pSUPER.retro with nontargeting shRNA sequence. pSUPER.retro with shABL-1 sequence (5'-AAAGGUGAAAAGCUCCGGGUC-3') [20, 55]; pGIPz/puro with shABL-2 (5'ATGCTTAGAGTGTTATCTC-3') and shABL-3 (5'-AATGGAGCGTGGTGATGAG-3') (shABL-2 and shABL-3 from Thermo Scientific). Note that the shAbl-3 targeting sequence is less efficient in downregulating $\mathrm{ABL}$ compared to shAbl-1 and shAbl-2. The moderate decrease of ABL levels in U87 $7^{\text {shAbl-3 }}$ cells is paralleled by a switch of some, but not all, molecular and cellular properties observed in U87 $7^{\text {shAbl-1 }}$ and U87 $7^{\text {shAbl-2 }}$ cells. Based on these findings, it is tempting to speculate that U87 $7^{\text {shAbl-3 }}$ cells underline a range of sensitivities to different $\mathrm{ABL}$ dosages. Below a certain threshold (modelled by U87 $7^{\text {shAbl-3 }}$ cells), ABL inputs are not permissive for some morphological, molecular, and biological properties. U87 $7^{\text {rescue }}$ cells were generated by transfecting U87 cells carrying shAbl-1 with pSGT-ABL ${ }^{\text {wt }}$ plasmid (kindly provided by D. Barilà). Vectors were transfected into cells by using Lipofectamine 2000 (Invitrogen Life Technologies), according to the manufacturer's instructions. Cells were selected with G418 and pools of resistant cells were used for experiments.

\section{Total RNA extraction and quantitative real-time PCR}

Total RNA was extracted from cells using the RNeasy mini kit (QIAGEN), processed with DNase (RNase-free DNase I Set, QIAGEN), and purified on RNAeasy column (QIAGEN). Reverse Transcription was then performed with iScript Reverse Transciption Supermix (Bio-Rad). mRNA levels were assessed in a qPCR CFX 96 apparatus (Bio-Rad). Amplifications were done using the SYBR ${ }^{\circledR}$ Green detection method. The target mRNA levels were normalized to the housekeeping gene Beta-2-microglobuline (B2M) and were analysed using the $2^{-\Delta \Delta C t}$ method. All reactions were run in triplicate and repeated in at least two independent experiments. The results are presented as n-fold changes versus the values in control cells. Primer sequences used are reported in Supplementary Table 2.

\section{Western blots and immunocytochemistry}

For western blots, protein extracts were biochemically analysed as previously described [84]. Antibodies used were anti-Actin (1:1000), anti-Tubulin (1:4000; Sigma), anti-Vimentin (1:500; AbCam), antiABL (1:1000; Calbiochem), anti-Mdm2 (1:3000; Oncogene), anti-FAK (1:1000), anti-E-Cadherin (1:5000; BD Transduction Labs), anti-ZO-1 (1:2000; Invitrogen Life Technologies), anti-Met (1:1000; sc-161), antiEGFR (1:1000; sc-03), anti-FGFR2 (1:1000; sc-122), anti-p53 (1:5000; sc-6243), anti-p70 ${ }^{\mathrm{S} 6 \mathrm{~K}}(1: 1000 ;$ sc230), anti-Cytokeratin 18 (1:100; sc-32329), antiCytokeratin 19 (1:200; sc-53003), anti-Twist (1:2000; H-81; Santa Cruz), anti-4EBP1 (1:500; 07-397; Upstate), anti-phosphotyrosine (1:1500; 4G10, Millipore), antiphosphoY $_{397}$-FAK (1:2000), anti-phosphoY ${ }_{861}$-FAK (1:1000), anti-phosphoY ${ }_{402}-\mathrm{Pyk} 2$ (1:2000; Biosource), anti-phosphoY ${ }_{412}$-ABL (1:1000), anti-phosphoY ${ }_{1234-1235}$ Met (1:2000), anti-PDGFR $\beta$ (1:1000), anti-Akt (1:2000), anti-phosphoS ${ }_{473}$-Akt (1:2000), anti-STAT3 (1:2000), antiphosphoS $_{727}$-STAT3 (1:2000), anti-phosphoY ${ }_{705}$-STAT3 (1:2000), anti-ERKs (1:10000), anti-phosphoT ${ }_{202} \mathrm{Y}_{204}{ }^{-}$ ERKs (1:10000), anti-phospho ${ }_{183} \mathrm{Y}_{185}$-JNK (1:1000), anti-phosphoT ${ }_{180} \mathrm{Y}_{182}$-p38 (1:2000), anti-phosphoS ${ }_{133}$ CREB (1:1000; this antibody also recognizes p-ATF1), anti-phospho $\mathrm{T}_{423} \mathrm{~T}_{402}$-PAK (1:1000), anti-phospho $\mathrm{T}_{389}$ p70 ${ }^{\mathrm{S} 6 \mathrm{~K}}(1: 1000)$, anti-phospho $\mathrm{T}_{421} \mathrm{~S}_{424}-\mathrm{p} 70^{\mathrm{S} 6 \mathrm{~K}}(1: 5000)$, anti-phosphoS ${ }_{392}$-p53 (1:1000; Cell Signaling). For screen studies of expression/phosphorylation levels, densitometric analysis was performed with the ImageJ software.

For immunocytochemistry, cells were cultured 
on coverslips, then fixed with $4 \%$ paraformaldehyde (PFA) for 10 minutes at room temperature. After permeabilization for 15 minutes with PBS-0.5\% TritonX-100, cells were incubated for $1 \mathrm{~h}$ with Alexa594conjugated phalloidin (Life Technologies), then washed in PBS- $0.1 \%$ TritonX100. Finally, coverslips were mounted in Prolong-Gold antifade reagent DAPI (Invitrogen Life Technologies).

\section{Time-lapse videomicroscopy}

U87, U87 $7^{\text {shABL}}$, and $\mathrm{U} 87^{\text {rescue }}$ cells $\left(1 \times 10^{4}\right)$ were seeded into $6 \mathrm{~cm}$ dishes and incubated under normal growth conditions for $24 \mathrm{~h}$. To avoid evaluating effects that would be secondary to changes in cell proliferation, all recordings were performed in presence of Cytosine arabinoside (AraC; $10 \mu \mathrm{M}$; Sigma), an inhibitor of DNA synthesis. Experiments were also performed in the absence of AraC. The dynamics of cell movement at $37^{\circ} \mathrm{C}$ and $5 \% \mathrm{CO}_{2}$ was monitored by time-lapse cinematography using an inverted optical microscope ObserverZ1 colibri1 (Zeiss) equipped with an incubator chamber placed on a motorized stage. One field per dish was selected and scanned sequentially every $5 \mathrm{~min}$ for $20 \mathrm{~h}$ at a magnification of $\times 10$. Image analyses and measurements were performed with the ImageJ software. In the first photograph the nucleus of at least 10 cells was marked and tracked to the last photograph. Direct distance from the start point to the end point, median velocity, as well as the time the cells were moving or not were calculated.

\section{Invasion assay}

U87 and U87 $7^{\text {shABL }}$ cells $\left(1 \times 10^{4}\right)$ were seeded in the upper compartment of $8 \mu \mathrm{m}$-pore Boyden-like chamber (transwell, Corning) pre-coated with $3.5 \mathrm{mg} / \mathrm{ml}$ Matrigel (BD Biosciences) in $200 \mu \mathrm{l}$ of RPMI supplemented with $0.5 \%$ FBS and $10 \mu \mathrm{M} \mathrm{AraC}$. The bottom chambers were filled with $700 \mu \mathrm{l}$ of complete RPMI media. After $24 \mathrm{~h}$ of incubation at $37^{\circ} \mathrm{C}$, non-invading cells present on the upper surface of the filter were removed with a cotton swab. The invading cells located on the underside were fixed with 4\% PFA and stained with a solution of 2\% Crystal Violet. Invasive ability was determined by counting cells that had migrated to the lower side of the filter. Experiments were performed in triplicate in at least 3 independent experiments.

\section{Cell proliferation and survival assays}

U87 and U87 ${ }^{\text {shABL }}$ cells were cultured for 2 and 5 days on glass coverslips. After pulsing with Bromodeoxyuridine (BrdU, Sigma) at a final concentration of $100 \mu \mathrm{M}$ for $6 \mathrm{~h}$, cells were fixed with 4\% PFA, permeabilized with PBS-
$0.5 \%$ TritonX-100 and denatured with $2 \mathrm{~N} \mathrm{HCl}$. Cells were washed with $0.1 \mathrm{M}$ sodium borate $(\mathrm{pH} 8.5)$ and incubated overnight at $4{ }^{\circ} \mathrm{C}$ with primary anti-BrdU monoclonal antibody (1:300, Sigma). Cells were then incubated for $1 \mathrm{~h}$ at room temperature with secondary donkey anti-rat Alexa 594 antibodies (1:500; Invitrogen Life Technologies). For immunostaining with AnnexinV, cells were fixed with $4 \%$ PFA, permeabilized with PBS- $0.5 \%$ TritonX-100 and incubated overnight at $4^{\circ} \mathrm{C}$ with anti-AnnexinV (1:100; Abcys), then for $1 \mathrm{~h}$ at room temperature with secondary goat anti-mouse Alexa 555 antibodies (1:500; Invitrogen Life Technologies). TUNEL was performed following protocol previously described [85]. Coverslips were mounted in Prolong-Gold antifade reagent DAPI.

\section{Soft agar assay}

U87, U87 $7^{\text {shABL }}$, U87 $7^{\text {rescue }}, \mathrm{LN} 19$, and LN229 cells were suspended in complete RPMI media containing $0.5 \%$ agar and seeded in triplicate on $35 \mathrm{~mm}$ dishes pre-coated with $1 \%$ agar in complete RPMI media and incubated at $37^{\circ} \mathrm{C}, 5 \% \mathrm{CO} 2$. After 2 weeks, colonies were stained with Thiazolyl Blue Tetrazolium Bromide (MTT) $(1 \mathrm{mg} / \mathrm{ml}$, Sigma), and counted. Numbers are expressed as means of triplicates.

\section{In vivo tumourigenesis assay}

$\mathrm{U} 87$ and $\mathrm{U} 87^{\text {shABL }}$ cells $\left(3 \times 10^{6}\right)$ resuspended in $150 \mu \mathrm{l}$ of PBS were injected sub-cutaneously into the flank of nude mice (S/SOPF SWISS NU/NU; Charles River). Mice were then sacrificed after $4(n=11)$ or $8(n=4)$ weeks of treatment. Tumour volume was determined from caliper measurements of tumour length (L) and width (W). The formula used for tumour volume measurement was: ( $\mathrm{L} \mathrm{x}$ $\left.\mathrm{W}^{2}\right) / 2$. All procedures involving the use of animals were performed in accordance with the European Community Council Directive of 22 September 2010 on the protection of animals used for experimental purposes (2010/63/UE). The experimental protocols were carried out in compliance with institutional Ethical Committee guidelines for animal research (comité d'éthique pour l'expérimentation animale - Comité d'éthique de Marseille; agreement number D13055-21 delivered by the Direction départementale des services vétérinaires - Préfecture des Bouches du Rhône).

\section{Tumour spheres-forming assay}

Cells were cultured at a density of $2 \times 10^{4} / 35 \mathrm{~mm}$ dishes in stem cell-permissive media as previously described [58]. After 10-14 days, spheres were collected and processed for total RNA extraction. For self-renewal assays, primary spheres were dissociated after 2 weeks into single cells and re-plated at the same density as 
previously described [58]. Subsphere-forming assay (also called passage) was repeated every 2 weeks. After each passage, number and size of spheres were analysed.

\section{Statistical analysis}

Results were expressed as the mean \pm s.e.m. Statistical significance of biological outcomes was analysed by the Mann-Whitney test when applicable, otherwise by the Student's- $t$ test. Statistical significance was defined as not significant (ns): $P>0.05$; $: P<0.05$; **: $P<0.01$; ***: $P<0.001$.

\section{Abbreviations}

GBM: Glioblastoma; RTK: Receptor Tyrosine Kinase; shRNA: short hairpin RNA; RT-qPCR: realtime quantitative PCR; ZO-1: Zonal occludens-1; DMEM: Dulbecco's modified Eagle's medium; FBS: Fetal Bovine Serum; B2M: Beta-2 microglobuline; PFA: Paraformaldehyde; AraC: Cytosine arabinoside; BrdU: Bromodeoxyuridine; MTT: Thiazolyl Blue Tetrazolium Bromide.

\section{ACKNOWLEDGMENTS}

We thank: R. Dono, R. Kelly, P. Durbec, M. Cayre, A. Porras, and all members of our labs for helpful discussions and comments; D. Barilà and V. Stagni for generating some $\mathrm{U} 87^{\mathrm{shABL}}$ and control cells, for ABL expression plasmid, and for discussion; A. Furlan for his contribution to part of xenograft studies shown in Figure 5D; V. Girod-David and L. Jullien for excellent help with mouse husbandry at the IBDM. This work was: funded by INCa (Institut National du Cancer), FdF (Fondation de France), ARC (Association pour la Recherche contre le Cancer), FRM (Fondation pour la Recherche Médicale), Fondation Bettencourt-Schueller to F.M; partially supported by INCa-DGOS-Inserm 6038 (SIRIC Label) to D.F.B. M.A. was supported by a Fondation de France postdoctoral fellowship; F.C. by an Associazione Italiana per la Ricerca sul Cancro (AIRC) postdoctoral fellowship and by a FRM grant to F.H. The contribution of the Region Provence Alpes Côtes d'Azur and of the Aix-Marseille Universite to the IBDM animal facility, and of the FranceBioImaging/PICsL infrastructure supported by the Agence Nationale de la Recherche (ANR-10-INSB-04-01, call "Investissements d'Avenir") for the Imaging facility, are also acknowledged.

\section{CONFLICTS OF INTEREST} interests.

\section{Authors' Contributions}

FL, ST, FC, MA, NB, and FM performed the experiments. FL, ST and FC contributed equally to the experimental work. FM directed the study. FH and DFB contributed reagents. FL and FM, with the contribution of $\mathrm{FH}$, wrote the manuscript. Final approval was given by all authors.

\section{REFERENCES}

1. Sirvent A, Benistant $\mathrm{C}$ and Roche $\mathrm{S}$. Cytoplasmic signalling by the c-Abl tyrosine kinase in normal and cancer cells. Biol Cell. 2008; 100(11):617-631.

2. Wang JY. The capable ABL: what is its biological function? Mol Cell Biol. 2014; 34(7):1188-1197.

3. Greuber EK, Smith-Pearson P, Wang J and Pendergast AM. Role of ABL family kinases in cancer: from leukaemia to solid tumours. Nat Rev Cancer. 2013; 13(8):559-571.

4. Woodring PJ, Hunter $\mathrm{T}$ and Wang JY. Regulation of F-actin-dependent processes by the Abl family of tyrosine kinases. J Cell Sci. 2003; 116(Pt 13):2613-2626.

5. Singh J, Yanfeng WA, Grumolato L, Aaronson SA and Mlodzik M. Abelson family kinases regulate Frizzled planar cell polarity signaling via Dsh phosphorylation. Genes Dev. 2010; 24(19):2157-2168.

6. Tamada M, Farrell DL and Zallen JA. Abl regulates planar polarized junctional dynamics through beta-catenin tyrosine phosphorylation. Dev Cell. 2012; 22(2):309-319.

7. Yang L, Lin C and Liu ZR. P68 RNA helicase mediates PDGF-induced epithelial mesenchymal transition by displacing Axin from beta-catenin. Cell. 2006; 127(1):139155.

8. Qiu Z, Cang Y and Goff SP. c-Abl tyrosine kinase regulates cardiac growth and development. Proc Natl Acad Sci U S A. 2010; 107(3):1136-1141.

9. Furlan A, Lamballe F, Stagni V, Hussain A, Richelme S, Prodosmo A, Moumen A, Brun C, Del Barco Barrantes I, Arthur JS, Koleske AJ, Nebreda AR, Barila D and Maina F. Met acts through Abl to regulate p53 transcriptional outcomes and cell survival in the developing liver. J Hepatol. 2012; 57(6):1292-1298.

10. Moresco EM and Koleske AJ. Regulation of neuronal morphogenesis and synaptic function by Abl family kinases. Curr Opin Neurobiol. 2003; 13(5):535-544.

11. Koleske AJ, Gifford AM, Scott ML, Nee M, Bronson RT, Miczek KA and Baltimore D. Essential roles for the Abl and Arg tyrosine kinases in neurulation. Neuron. 1998; 21(6):1259-1272.

12. Qiu Z, Cang Y and Goff SP. Abl family tyrosine kinases are essential for basement membrane integrity and cortical lamination in the cerebellum. J Neurosci. 2010; 30(43):14430-14439. 
13. Gonfloni S, Di Tella L, Caldarola S, Cannata SM, Klinger FG, Di Bartolomeo C, Mattei M, Candi E, De Felici M, Melino G and Cesareni G. Inhibition of the c-Abl-TAp63 pathway protects mouse oocytes from chemotherapyinduced death. Nat Med. 2009; 15(10):1179-1185.

14. Gonfloni S, Maiani E, Di Bartolomeo C, Diederich M and Cesareni G. Oxidative Stress, DNA Damage, and c-Abl Signaling: At the Crossroad in Neurodegenerative Diseases? International journal of cell biology. 2012; 2012:683097.

15. Hantschel O and Superti-Furga G. Regulation of the c-Abl and Bcr-Abl tyrosine kinases. Nat Rev Mol Cell Biol. 2004; 5(1):33-44.

16. Srinivasan D and Plattner R. Activation of Abl tyrosine kinases promotes invasion of aggressive breast cancer cells. Cancer Res. 2006; 66(11):5648-5655.

17. Rikova K, Guo A, Zeng Q, Possemato A, Yu J, Haack H, Nardone J, Lee K, Reeves C, Li Y, Hu Y, Tan Z, Stokes M, et al. Global survey of phosphotyrosine signaling identifies oncogenic kinases in lung cancer. Cell. 2007; 131(6):11901203.

18. Ganguly SS, Fiore LS, Sims JT, Friend JW, Srinivasan D, Thacker MA, Cibull ML, Wang C, Novak M, Kaetzel DM and Plattner R. c-Abl and Arg are activated in human primary melanomas, promote melanoma cell invasion via distinct pathways, and drive metastatic progression. Oncogene. 2011.

19. Podtcheko A, Ohtsuru A, Tsuda S, Namba H, Saenko V, Nakashima M, Mitsutake N, Kanda S, Kurebayashi J and Yamashita S. The selective tyrosine kinase inhibitor, STI571, inhibits growth of anaplastic thyroid cancer cells. The Journal of clinical endocrinology and metabolism. 2003; 88(4):1889-1896.

20. Furlan A, Stagni V, Hussain A, Richelme S, Conti F, Prodosmo A, Destro A, Roncalli M, Barila D and Maina F. $\mathrm{Abl}$ interconnects oncogenic Met and p53 core pathways in cancer cells. Cell Death Differ. 2011; 18(10):1608-1616.

21. Schmandt RE, Broaddus R, Lu KH, Shvartsman H, Thornton A, Malpica A, Sun C, Bodurka DC and Gershenson DM. Expression of c-ABL, c-KIT, and plateletderived growth factor receptor-beta in ovarian serous carcinoma and normal ovarian surface epithelium. Cancer. 2003; 98(4):758-764.

22. Ganguly SS and Plattner R. Activation of abl family kinases in solid tumors. Genes \& cancer. 2012; 3(5-6):414-425. doi: $10.1177 / 1947601912458586$.

23. Wang $J$ and Pendergast AM. The Emerging Role of ABL Kinases in Solid Tumors. Trends Cancer. 2015; 1(2):110123.

24. Plattner R, Kadlec L, DeMali KA, Kazlauskas A and Pendergast AM. c-Abl is activated by growth factors and Src family kinases and has a role in the cellular response to PDGF. Genes Dev. 1999; 13(18):2400-2411.

25. Furstoss O, Dorey K, Simon V, Barila D, Superti-Furga G and Roche S. c-Abl is an effector of Src for growth factor- induced c-myc expression and DNA synthesis. Embo J. 2002; 21(4):514-524.

26. Yusuf D, Butland SL, Swanson MI, Bolotin E, Ticoll A, Cheung WA, Zhang XY, Dickman CT, Fulton DL, Lim JS, Schnabl JM, Ramos OH, Vasseur-Cognet M, et al. The transcription factor encyclopedia. Genome Biol. 2012;13:R24. doi: 10.1186/gb-2012-13-3-r24.

27. Podar K, Raab MS, Tonon G, Sattler M, Barila D, Zhang J, Tai YT, Yasui H, Raje N, DePinho RA, Hideshima T, Chauhan D and Anderson KC. Up-regulation of c-Jun inhibits proliferation and induces apoptosis via caspasetriggered c-Abl cleavage in human multiple myeloma. Cancer Res. 2007; 67(4):1680-1688.

28. Frasca F, Vigneri P, Vella V, Vigneri R and Wang JY. Tyrosine kinase inhibitor STI571 enhances thyroid cancer cell motile response to Hepatocyte Growth Factor. Oncogene. 2001; 20(29):3845-3856.

29. Kain $\mathrm{KH}$ and Klemke RL. Inhibition of cell migration by Abl family tyrosine kinases through uncoupling of CrkCAS complexes. J Biol Chem. 2001; 276(19):16185-16192.

30. Kain KH, Gooch S and Klemke RL. Cytoplasmic c-Abl provides a molecular 'Rheostat' controlling carcinoma cell survival and invasion. Oncogene. 2003; 22(38):6071-6080.

31. Noren NK, Foos G, Hauser CA and Pasquale EB. The EphB4 receptor suppresses breast cancer cell tumorigenicity through an Abl-Crk pathway. Nat Cell Biol. 2006; 8(8):815825 .

32. Rix U, Hantschel O, Durnberger G, Remsing Rix LL, Planyavsky M, Fernbach NV, Kaupe I, Bennett KL, Valent P, Colinge J, Kocher T and Superti-Furga G. Chemical proteomic profiles of the BCR-ABL inhibitors imatinib, nilotinib, and dasatinib reveal novel kinase and nonkinase targets. Blood. 2007; 110(12):4055-4063.

33. Lombardo LJ, Lee FY, Chen P, Norris D, Barrish JC, Behnia K, Castaneda S, Cornelius LA, Das J, Doweyko AM, Fairchild C, Hunt JT, Inigo I, et al. Discovery of N-(2-chloro-6-methyl- phenyl)-2-(6-(4-(2-hydroxyethyl)piperazin-1-yl)-2-methylpyrimidin-4- ylamino)thiazole5-carboxamide (BMS-354825), a dual Src/Abl kinase inhibitor with potent antitumor activity in preclinical assays. J Med Chem. 2004; 47(27):6658-6661.

34. Huang F, Reeves K, Han X, Fairchild C, Platero S, Wong TW, Lee F, Shaw P and Clark E. Identification of candidate molecular markers predicting sensitivity in solid tumors to dasatinib: rationale for patient selection. Cancer Res. 2007; 67(5):2226-2238.

35. Gonfloni S. Defying c-Abl signaling circuits through small allosteric compounds. Frontiers in genetics. 2014; 5:392.

36. Maher EA, Furnari FB, Bachoo RM, Rowitch DH, Louis DN, Cavenee WK and DePinho RA. Malignant glioma: genetics and biology of a grave matter. Genes Dev. 2001; 15(11):1311-1333.

37. Stupp R, Hegi ME, Gilbert MR and Chakravarti A. Chemoradiotherapy in malignant glioma: standard of care 
and future directions. J Clin Oncol. 2007; 25(26):41274136.

38. Stupp R, Mason WP, van den Bent MJ, Weller M, Fisher B, Taphoorn MJ, Belanger K, Brandes AA, Marosi C, Bogdahn U, Curschmann J, Janzer RC, Ludwin SK, et al. Radiotherapy plus concomitant and adjuvant temozolomide for glioblastoma. The New England journal of medicine. 2005; 352(10):987-996.

39. Galli R, Binda E, Orfanelli U, Cipelletti B, Gritti A, De Vitis S, Fiocco R, Foroni C, Dimeco F and Vescovi A. Isolation and characterization of tumorigenic, stem-like neural precursors from human glioblastoma. Cancer Res. 2004; 64(19):7011-7021.

40. Singh SK, Hawkins C, Clarke ID, Squire JA, Bayani J, Hide T, Henkelman RM, Cusimano MD and Dirks PB. Identification of human brain tumour initiating cells. Nature. 2004; 432(7015):396-401.

41. Yuan X, Curtin J, Xiong Y, Liu G, Waschsmann-Hogiu S, Farkas DL, Black KL and Yu JS. Isolation of cancer stem cells from adult glioblastoma multiforme. Oncogene. 2004; 23(58):9392-9400.

42. Lee J, Kotliarova S, Kotliarov Y, Li A, Su Q, Donin NM, Pastorino S, Purow BW, Christopher N, Zhang W, Park JK and Fine HA. Tumor stem cells derived from glioblastomas cultured in bFGF and EGF more closely mirror the phenotype and genotype of primary tumors than do serumcultured cell lines. Cancer Cell. 2006; 9(5):391-403.

43. Gilbertson RJ and Rich JN. Making a tumour's bed: glioblastoma stem cells and the vascular niche. Nat Rev Cancer. 2007; 7(10):733-736.

44. Network TCGAR. Comprehensive genomic characterization defines human glioblastoma genes and core pathways. Nature. 2008; 455(7216):1061-1068.

45. Stommel JM, Kimmelman AC, Ying H, Nabioullin R, Ponugoti AH, Wiedemeyer R, Stegh AH, Bradner JE, Ligon KL, Brennan C, Chin L and DePinho RA. Coactivation of receptor tyrosine kinases affects the response of tumor cells to targeted therapies. Science. 2007; 318(5848):287-290.

46. Maina F. Strategies to overcome drug resistance of receptor tyrosine kinaseaddicted cancer cells. Current medicinal chemistry. 2014; 21(14):1607-1617.

47. Srinivasan D, Kaetzel DM and Plattner R. Reciprocal Regulation of Abl and Receptor Tyrosine Kinases. Cell Signal. 2009.

48. Lu-Emerson C, Norden AD, Drappatz J, Quant EC, Beroukhim R, Ciampa AS, Doherty LM, Lafrankie DC, Ruland S and Wen PY. Retrospective study of dasatinib for recurrent glioblastoma after bevacizumab failure. J Neurooncol. 2011; 104(1):287-291.

49. Haberler C, Gelpi E, Marosi C, Rossler K, Birner P, Budka $\mathrm{H}$ and Hainfellner JA. Immunohistochemical analysis of platelet-derived growth factor receptor-alpha, -beta, c-kit, c-abl, and arg proteins in glioblastoma: possible implications for patient selection for imatinib mesylate therapy. J Neurooncol. 2006; 76(2):105-109.

50. Martinho O, Silva-Oliveira R, Miranda-Goncalves V, Clara C, Almeida JR, Carvalho AL, Barata JT and Reis RM. In Vitro and In Vivo Analysis of RTK Inhibitor Efficacy and Identification of Its Novel Targets in Glioblastomas. Translational oncology. 2013; 6(2):187-196.

51. Lal B, Goodwin CR, Sang Y, Foss CA, Cornet K, Muzamil $\mathrm{S}$, Pomper MG, Kim J and Laterra J. EGFRvIII and c-Met pathway inhibitors synergize against PTEN-null/ EGFRvIII+ glioblastoma xenografts. Mol Cancer Ther. 2009; 8(7):1751-1760.

52. Zhang X, Lv H, Zhou Q, Elkholi R, Chipuk JE, Reddy MV, Reddy EP and Gallo JM. Preclinical pharmacological evaluation of a novel multiple kinase inhibitor, ON123300, in brain tumor models. Mol Cancer Ther. 2014; 13(5):11051116.

53. Martens $\mathrm{T}$, Schmidt NO, Eckerich C, Fillbrandt R, Merchant M, Schwall R, Westphal M and Lamszus K. A novel one-armed anti-c-Met antibody inhibits glioblastoma growth in vivo. Clin Cancer Res. 2006; $12(20$ Pt 1):61446152.

54. Furlan A, Roux B, Lamballe F, Conti F, Issaly N, Daian F, Guillemot JF, Richelme S, Contensin M, Bosch J, Passarella D, Piccolo O, Dono R and Maina F. Combined drug action of 2-phenylimidazo [2,1-b]benzothiazole derivatives on cancer cells according to their oncogenic molecular signatures. PLoS One. 2012; 7(10):e46738.

55. Machuy N, Rajalingam K and Rudel T. Requirement of caspase-mediated cleavage of c-Abl during stress-induced apoptosis. Cell Death Differ. 2004; 11(3):290-300.

56. Truong T, Sun G, Doorly M, Wang JY and Schwartz MA. Modulation of DNA damage-induced apoptosis by cell adhesion is independently mediated by p53 and c-Abl. Proc Natl Acad Sci U S A. 2003; 100(18):10281-10286.

57. Yu SC, Ping YF, Yi L, Zhou ZH, Chen JH, Yao XH, Gao $\mathrm{L}$, Wang JM and Bian XW. Isolation and characterization of cancer stem cells from a human glioblastoma cell line U87. Cancer Lett. 2008; 265(1):124-134.

58. Tchoghandjian A, Baeza N, Colin C, Cayre M, Metellus P, Beclin C, Ouafik L and Figarella-Branger D. A2B5 cells from human glioblastoma have cancer stem cell properties. Brain Pathol. 2010; 20(1):211-221.

59. Tchoghandjian A, Baeza-Kallee N, Beclin C, Metellus P, Colin C, Ducray F, Adelaide J, Rougon G and FigarellaBranger D. Cortical and Subventricular Zone GlioblastomaDerived Stem-Like Cells Display Different Molecular Profiles and Differential In Vitro and In Vivo Properties. Annals of surgical oncology. 2011.

60. Baruchel S, Sharp JR, Bartels U, Hukin J, Odame I, Portwine C, Strother D, Fryer C, Halton J, Egorin MJ, Reis RM, Martinho O, Stempak D, Hawkins C, Gammon J and Bouffet E. A Canadian paediatric brain tumour consortium (CPBTC) phase II molecularly targeted study of imatinib in recurrent and refractory paediatric central nervous system 
tumours. Eur J Cancer. 2009; 45(13):2352-2359.

61. Sridevi P, Nhiayi MK, Setten RL and Wang JY. Persistent inhibition of ABL tyrosine kinase causes enhanced apoptotic response to TRAIL and disrupts the pro-apoptotic effect of chloroquine. PLoS One. 2013; 8(10):e77495.

62. Bradley WD and Koleske AJ. Regulation of cell migration and morphogenesis by Abl-family kinases: emerging mechanisms and physiological contexts. J Cell Sci. 2009; 122(Pt 19):3441-3454.

63. Smith-Pearson PS, Greuber EK, Yogalingam G and Pendergast AM. Abl kinases are required for invadopodia formation and chemokine-induced invasion. J Biol Chem. 2010; 285(51):40201-40211.

64. Gil-Henn H, Patsialou A, Wang Y, Warren MS, Condeelis JS and Koleske AJ. Arg/Abl2 promotes invasion and attenuates proliferation of breast cancer in vivo. Oncogene. 2013; 32(21):2622-2630.

65. Snuderl M, Fazlollahi L, Le LP, Nitta M, Zhelyazkova BH, Davidson CJ, Akhavanfard S, Cahill DP, Aldape $\mathrm{KD}$, Betensky RA, Louis DN and Iafrate AJ. Mosaic amplification of multiple receptor tyrosine kinase genes in glioblastoma. Cancer Cell. 2011; 20(6):810-817.

66. Little SE, Popov S, Jury A, Bax DA, Doey L, Al-Sarraj $\mathrm{S}$, Jurgensmeier JM and Jones C. Receptor tyrosine kinase genes amplified in glioblastoma exhibit a mutual exclusivity in variable proportions reflective of individual tumor heterogeneity. Cancer Res. 2012; 72(7):1614-1620.

67. Li MY, Yang P, Liu YW, Zhang CB, Wang KY, Wang YY, Yao K, Zhang W, Qiu XG, Li WB, Peng XX, Wang YZ and Jiang T. Low c-Met expression levels are prognostic for and predict the benefits of temozolomide chemotherapy in malignant gliomas. Scientific reports. 2016; 6:21141.

68. Kim HS, Li A, Ahn S, Song H and Zhang W. Inositol Polyphosphate-5-Phosphatase F (INPP5F) inhibits STAT3 activity and suppresses gliomas tumorigenicity. Scientific reports. 2014; 4:7330.

69. Wagner EF and Nebreda AR. Signal integration by JNK and p38 MAPK pathways in cancer development. Nat Rev Cancer. 2009; 9(8):537-549.

70. Luwor RB, Stylli SS and Kaye AH. The role of Stat3 in glioblastoma multiforme. Journal of clinical neuroscience. 2013; 20(7):907-911.

71. Thiery JP, Acloque H, Huang RY and Nieto MA. Epithelialmesenchymal transitions in development and disease. Cell. 2009; 139(5):871-890.

72. Mani SA, Guo W, Liao MJ, Eaton EN, Ayyanan A, Zhou AY, Brooks M, Reinhard F, Zhang CC, Shipitsin M, Campbell LL, Polyak K, Brisken C, Yang J and Weinberg RA. The epithelial-mesenchymal transition generates cells with properties of stem cells. Cell. 2008; 133(4):704-715.

73. Morel AP, Lievre M, Thomas C, Hinkal G, Ansieau S and Puisieux A. Generation of breast cancer stem cells through epithelial-mesenchymal transition. PLoS One. 2008; 3(8):e2888.
74. Wellner U, Schubert J, Burk UC, Schmalhofer O, Zhu F, Sonntag A, Waldvogel B, Vannier C, Darling D, zur Hausen A, Brunton VG, Morton J, Sansom O, et al. The EMT-activator ZEB1 promotes tumorigenicity by repressing stemness-inhibiting microRNAs. Nat Cell Biol. 2009; 11(12):1487-1495.

75. Ocana OH, Corcoles R, Fabra A, Moreno-Bueno G, Acloque H, Vega S, Barrallo-Gimeno A, Cano A and Nieto MA. Metastatic colonization requires the repression of the epithelial-mesenchymal transition inducer Prrx1. Cancer Cell. 2012; 22(6):709-724.

76. Brabletz T. EMT and MET in metastasis: where are the cancer stem cells? Cancer Cell. 2012; 22(6):699-701.

77. Beerling E, Seinstra D, de Wit E, Kester L, van der Velden D, Maynard C, Schafer R, van Diest P, Voest E, van Oudenaarden A, Vrisekoop N and van Rheenen J. Plasticity between Epithelial and Mesenchymal States Unlinks EMT from Metastasis-Enhancing Stem Cell Capacity. Cell reports. 2016; 14(10):2281-2288.

78. Zhao C, Chen A, Jamieson CH, Fereshteh M, Abrahamsson A, Blum J, Kwon HY, Kim J, Chute JP, Rizzieri D, Munchhof M, VanArsdale T, Beachy PA and Reya T. Hedgehog signalling is essential for maintenance of cancer stem cells in myeloid leukaemia. Nature. 2009; 458(7239):776-779.

79. Dierks C, Beigi R, Guo GR, Zirlik K, Stegert MR, Manley P, Trussell C, Schmitt-Graeff A, Landwerlin K, Veelken H and Warmuth M. Expansion of Bcr-Abl-positive leukemic stem cells is dependent on Hedgehog pathway activation. Cancer Cell. 2008; 14(3):238-249.

80. Milano V, Piao Y, LaFortune T and de Groot J. Dasatinibinduced autophagy is enhanced in combination with temozolomide in glioma. Mol Cancer Ther. 2009; 8(2):394406.

81. Ren H, Tan X, Dong Y, Giese A, Chou TC, Rainov N and Yang B. Differential effect of imatinib and synergism of combination treatment with chemotherapeutic agents in malignant glioma cells. Basic \& clinical pharmacology \& toxicology. 2009; 104(3):241-252.

82. Alpay K, Farshchian M, Tuomela J, Sandholm J, Aittokallio K, Siljamaki E, Kallio M, Kahari VM and Hietanen S. Inhibition of c-Abl kinase activity renders cancer cells highly sensitive to mitoxantrone. PLoS One. 2014; 9(8):e105526.

83. Wang XD, Reeves K, Luo FR, Xu LA, Lee F, Clark E and Huang F. Identification of candidate predictive and surrogate molecular markers for dasatinib in prostate cancer: rationale for patient selection and efficacy monitoring. Genome biology. 2007; 8(11):R255.

84. Furlan A, Colombo F, Kover A, Issaly N, Tintori C, Angeli L, Leroux V, Letard S, Amat M, Asses Y, Maigret B, Dubreuil P, Botta M, et al. Identification of new aminoacid amides containing the imidazo [2,1-b]benzothiazol-2ylphenyl moiety as inhibitors of tumorigenesis by oncogenic Met signaling. Eur J Med Chem. 2012; 47(1):239-254. 
85. Tulasne D, Deheuninck J, Lourenco FC, Lamballe F, Ji Z, Leroy C, Puchois E, Moumen A, Maina F, Mehlen P and Fafeur V. Proapoptotic function of the MET tyrosine kinase receptor through caspase cleavage. Mol Cell Biol. 2004; 24(23):10328-10339. 